\title{
VEGFR2 induces c-Src signaling and vascular permeability in vivo via the adaptor protein TSAd
}

\author{
Zuyue Sun, ${ }^{1}$ Xiujuan Li, ${ }^{1}$ Sara Massena, ${ }^{2}$ Simone Kutschera, ${ }^{1}$ \\ Narendra Padhan, ${ }^{1}$ Laura Gualandi, ${ }^{1}$ Vibeke Sundvold-Gjerstad, ${ }^{4}$ \\ Karin Gustafsson, ${ }^{2}$ Wing Wen Choy, ${ }^{3}$ Guangxiang Zang, ${ }^{2}$ My Quach, ${ }^{2}$ \\ Leif Jansson, ${ }^{2}$ Mia Phillipson, ${ }^{2}$ Md Ruhul Abid, ${ }^{5}$ Anne Spurkland, ${ }^{4}$ \\ and Lena Claesson-Welsh ${ }^{1}$
}

1Department of Immunology, Genetics and Pathology, Rudbeck Laboratory, Uppsala University, 75185 Uppsala, Sweden
2Department of Medical Cell Biology, Biomedical Center, Uppsala University, 75123 Uppsala, Sweden
3Beth Israel Deaconess Medical Center, Harvard Medical School, Boston, MA 02215
${ }^{4}$ Institute of Basal Medical Sciences, University of Oslo, 0317 Oslo, Norway
${ }^{5}$ Department of Cardiothoracic Surgery, Brown University Warren Alpert Medical School, Rhode Island Hospital, Providence, RI 02903

Regulation of vascular endothelial (VE) growth factor (VEGF)-induced permeability is critical in physiological and pathological processes. We show that tyrosine phosphorylation of VEGF receptor 2 (VEGFR2) at Y951 facilitates binding of VEGFR2 to the Rous sarcoma (Src) homology 2-domain of T cell-specific adaptor (TSAd), which in turn regulates VEGFinduced activation of the c-Src tyrosine kinase and vascular permeability. c-Src was activated in vivo and in vitro in a VEGF/TSAd-dependent manner, and was regulated via increased phosphorylation at pY418 and reduced phosphorylation at pY527. Tsad silencing blocked VEGF-induced c-Src activation, but did not affect pathways involving phospholipase $C \gamma$, extracellular regulated kinase, and endothelial nitric oxide. VEGF-induced rearrangement of VE-cadherin-positive junctions in endothelial cells isolated from mouse lungs, or in mouse cremaster vessels, was dependent on TSAd expression, and TSAd formed a complex with VE-cadherin, VEGFR2, and c-Src at endothelial junctions. Vessels in tsad ${ }^{-1}$ mice showed undisturbed flow and pressure, but impaired VEGF-induced permeability, as measured by extravasation of Evans blue, dextran, and microspheres in the skin and the trachea. Histamine-induced extravasation was not affected by TSAd deficiency. We conclude that TSAd is required for VEGF-induced, c-Src-mediated regulation of endothelial cell junctions and for vascular permeability.

CORRESPONDENCE

Lena Claesson-Welsh:

Lena.Welsh@igp.uu.se

Abbreviations used: HDMEC, human dermal microvascular endothelial cell; pI, isoelectric point; Src, Rous sarcoma; TSAd, T cell-specific adapter; VE, vascular endothelial; VEGF, VE growth factor; VPF, vascular permeability factor.
Vascular endothelial (VE) growth factor (VEGF) promotes migration, proliferation, and organization of endothelial cells to form vascular structures during development and in the adult (Koch et al., 2011). The original designation for VEGF, vascular permeability factor (VPF), indicates its potent regulation of vessel integrity (Senger et al., 1983). Permeability to solute and proteins is of critical importance both in physiological and pathological conditions (Mehta and Malik, 2006; Vestweber, 2012). For example, extravasation of fibronectin and other extracellular matrix proteins in response toVEGF/VPF allows formation

Z. Sun, X. Li, and S. Massena contributed equally to this paper. $Z$. Sun's present address is University of Hawaii, College of

Pharmacy, Dept. of Pharmaceutical Sciences, Hilo, Hawaii 96720. of a provisional matrix for angiogenic sprouting (Dvorak et al., 1999). Chronic hyperpermeability resulting in persistent edema occurs in conjunction with pathologies involving inflammation, such as cancer (Nagy et al., 2008). Persistent edema interferes with treatment of cancer by elevating the intratumor interstitial pressure leading to poor perfusion and tissue hypoxia (Stohrer et al., 2000).

Two main mechanisms have been proposed for induction of VEGF-regulated vascular

Q 2012 Sun et al. This article is distributed under the terms of an AttributionNoncommercial-Share Alike-No Mirror Sites license for the first six months after the publication date (see http://www.rupress.org/terms). After six months it is available under a Creative Commons License (Attribution-Noncommercial-Share Alike 3.0 Unported license, as described at http://creativecommons.org/licenses/ by-nc-sa/3.0/). 
permeability, namely, formation of transendothelial pores and transient opening of endothelial cell-cell junctions. Transendothelial pores may be created in a caveolin-dependent manner from interconnected clusters of vesicles and vacuoles (the vesiculo vacuolar organelle) that traverse the venular endothelium (Feng et al., 2002). Endothelial junctions are composed of tight junctions and endothelial cell-specific adherens junctions. Opening of adherens junctions requires dissolution of homophilic vascular-endothelial cadherin (VE-cadherin) complexes in response to c-Rous sarcoma (Src)-dependent tyrosine phosphorylation of VE-cadherin (Scheppke et al., 2008). Rearrangement of the actin cytoskeleton and altered interactions with the extracellular matrix further support the opening of junctions (Vandenbroucke et al., 2008).

VEGF transduces its effects by binding to receptor tyrosine kinases VEGFR1 and VEGFR2, of which VEGFR2 is believed to be the main signal transducer in endothelial cells (Koch et al., 2011). Several tyrosine residues in the VEGFR2 intracellular domain have been identified as phosphorylation sites, including Y951, Y1054, Y1059, Y1175, and Y1214 in the human VEGFR2 (Takahashi et al., 2001; Matsumoto et al., 2005). Yet other tyrosine residues including Y801, Y996, and Y1008 have been implicated in VEGFR2 signaling (Dougher-Vermazen et al., 1994; Meyer et al., 2003; Solowiej et al., 2009). Whereas pY1054 and pY1059 serve as positive regulatory sites, $\mathrm{pY} 1175$ binds the adaptor molecules Shb (Holmqvist et al., 2004) and Sck (Warner et al., 2000), as

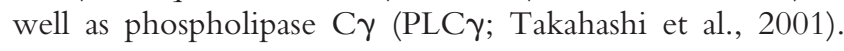
Exchange of the Y1173 residue in mouse VEGFR2 (Y1175 in human VEGFR2) for phenylalanine results in arrested endothelial cell development and embryonic death, similar to the global vegfr $2^{-/-}$phenotype (Sakurai et al., 2005). In contrast, mice with an Y1214F mutation survive development and show no obvious phenotype. The pY951 residue in VEGFR2 mediates binding of the $\mathrm{T}$ cell-specific adapter (TSAd), which is essential for endothelial cell actin reorganization and cell migration in vitro (Matsumoto et al., 2005), through regulation of c-Src activity (Matsumoto et al., 2005; Ruan and Kazlauskas, 2012). Activation of c-Src has also been shown to involve the adaptor molecule Grb-2-associated binder 1 (Laramée et al., 2007). Moreover, Y1059 in the VEGFR2 kinase activation loop binds c-Src, which thereby may phosphorylate other tyrosine residues in VEGFR2 (Meyer et al., 2008). The mechanism whereby VEGF activates $\mathrm{c}-\mathrm{Src}$ in vivo has however remained unclear.

TSAd is a classical signal adapter molecule, equipped with a central SH2 domain and a C-terminal proline-rich domain, as well as C-terminal tyrosine phosphorylation sites (Spurkland et al., 1998; Choi et al., 1999; Rajagopal et al., 1999; Wu et al., 2000). In vivo, TSAd is expressed in certain immune cells and endothelial cells (Sundvold-Gjerstad et al., 2007). Activation of the $\mathrm{T}$ cell receptor promotes complex formation between TSAd and the Src kinase family member Lck (Sundvold-Gjerstad et al., 2005). Tsad ${ }^{-/-}$mice may develop an autoimmune condition with advanced age (Drappa et al., 2003) although the penetrance is variable. Younger unchallenged mice lack apparent phenotype.

In this study, we show that VEGFR2-mediated c-Src activation and subsequent VEGF-induced vascular permeability requires TSAd. VEGF promotes phosphorylation of c-Src at Y418 and dephosphorylation at Y527, and active c-Src is located in focal adhesions and in endothelial cell adherens
A

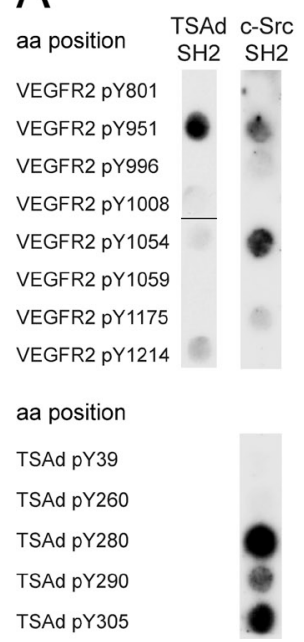

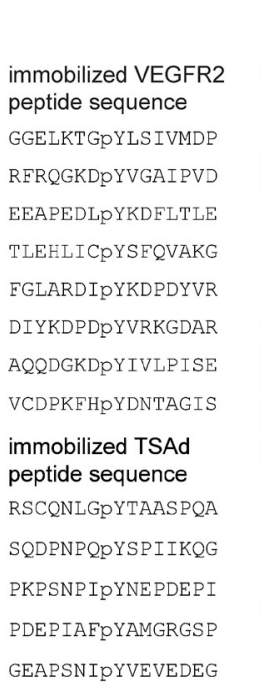

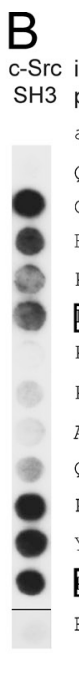

c-Src immobilized TSAd peptide sequence aa230 QKEGAGEKEPSQLLRPKPPI GAGEKEPS LLRPKPPIPAK EKEPSO LLRPKPPIPAKPL PSO LLRPKPPIPAKPQLPPE LLRPKPPIPAKPQLPPEVYT PKPPI PAKPQLP PEVYTIPV PI PAKPQL PPEVYT I PVPRH AKPQLPPEVYTIPVPRHRPA QLPPEVYTIPVPRHRPAPRP PEVYT I PVPRHRPAPRPKS YT I PVPRHRPAPRPKPSNPI EVRRHRPAPRPKPSNPIYNE RHRPAPRPKPSNPIYNEPDE aa285

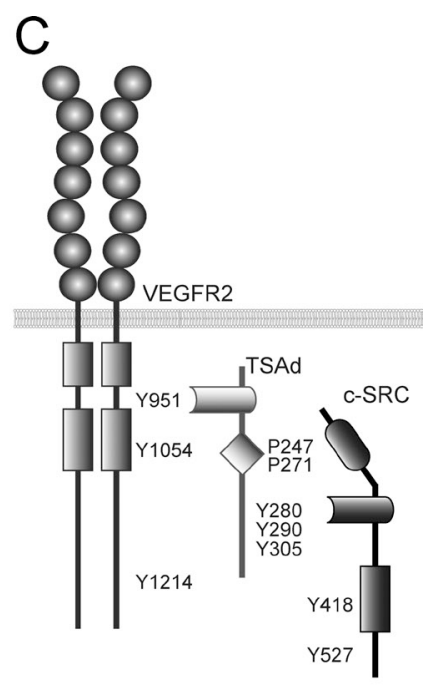

Figure 1. TSAd interactions with VEGFR2 and Src. (A) Immobilized peptides corresponding to tyrosine phosphorylation sites in VEGFR2 and TSAd were probed using TSAd GST-SH2 (left) or c-Src GST-SH2 (right) domain fusion proteins. The phosphotyrosine position in VEGFR2 or TSAd is indicated to the left and the peptide sequence to the right in the figure. The figure shows representative results from three independent experiments. Line indicates the splice of two parts of the same filter aligned to one strip. (B) Immobilized peptides corresponding to proline-rich stretches in TSAd were probed with c-Src GST-SH3 domain fusion protein. Peptide sequences are shown to the right. The figure shows representative results from three independent experiments. Line indicates the splice of two parts of the same filter aligned to one strip. (C) Schematic representation of VEGFR2, TSAd, and c-Src molecular interactions. 
junctions. TSAd deficiency is accompanied by loss of VEGF-induced c-Src activation in vitro and in vivo. As a consequence, endothelial cell junctions fail to rearrange in response to VEGF, and there is arrest in VEGF-induced vascular permeability. The vascular phenotype of $t s a d^{-/-}$mice demonstrates, in an in vivo setting, the essential role of TSAd-regulated c-Src signal transduction in dynamic regulation of VE-cadherinpositive adherens junction, which is required forVEGF-induced vascular permeability. These data provide the basis for new therapeutic strategies to specifically modulate excess VEGF-induced permeability and consequent edema in pathologies such as cancer.

\section{RESULTS}

TSAd binds to pY951 in VEGFR2 and presents multiple binding sites for c-Src-SH2 and SH3 domains

We previously showed that VEGFR2 forms a transient complex with TSAd and c-Src in VEGF-stimulated endothelial cells in vitro and implicated the phosphorylation site Y951 (Y949 in the mouse) as a TSAd-binding site (Matsumoto et al., 2005). To extend these data, we now used a GST-TSAd-SH2 fusion protein to probe a filter spotted with phosphopeptides corresponding to major phosphorylation sites in VEGFR2, i.e., pY951, pY1054,pY1059, pY1175, and pY1214 (Matsumoto et al., 2005). In addition, phosphopeptides were synthesized that included other tyrosine residues implicated in VEGFR2 signaling, such as Y801 (Solowiej et al., 2009), Y996 (DougherVermazen et al., 1994), and Y1008 (Meyer et al., 2003). As shown in Fig. 1 A, the TSAd-SH2 domain bound strongly to the pY951 phosphopeptide and much less to the pY1214 phosphopeptide. We conclude that pY951 and its surrounding sequence in VEGFR2 presents a major binding site for TSAd.

To show how c-Src interacts with VEGFR2 and TSAd, we tested binding of a GST-c-Src-SH2 probe to the VEGFR2 phosphopeptides, as well as to phosphopeptides representing the five previously reported tyrosine phosphorylation sites on TSAd; pY39, pY260, pY280, pY290, and pY305 (Granum et al., 2008). The GST-c-Src-SH2 probe bound weakly to pY951 and more efficiently to pY1054, which is located on the kinase activation loop of VEGFR2. Mutation of Y1054 to $\mathrm{F}$ is not compatible with kinase activity (Matsumoto et al., 2005). Furthermore, binding of c-Src to the VEGFR2 kinase activation loop is likely to interfere with kinase activity. The strongest binding of GST-c-Src-SH2 overall was to the TSAd pY280 peptide, although the pY290 and pY305-containing peptides also presented efficient binding sites. Proline-rich sequences in TSAd have been shown to bind to the $\mathrm{SH} 3$ domain

Figure 2. Impaired VEGF-induced extravasation of Evans blue and FITC-dextran in TSAd-deficient mice. (A) Systemic (i.v.) administration of Evans blue in WT and $\mathrm{tsad}^{-/-}$mice was followed $2 \mathrm{~h}$ later by intradermal injection of vehicle or VEGF (100 ng) on the back. Evans blue dye leakage in dorsal skin was assessed after 30 min. Representative images of three independent experiments using two to four mice/genotype each time with similar result. Bar, $5 \mathrm{~mm}$. (B) Quantification of extravasated Evans blue by formamide extraction from skin samples in $A_{\text {, corrected }}$ for tissue weight. $n=5$ (WT) and $6\left(\right.$ tsad $\left.^{-/-}\right)$ mice/genotype from 2 independent experiments. ${ }^{*}, P<0.05 ;{ }^{* *}, P<0.01$. (C) Basal extravasation of systemically delivered Evans blue in kidney, lung, and skin as quantified by formamide extraction. $n=3$ mice/genotype. Experiment was performed once. (D) Intradermal injection of vehicle or VEGF in the ear was followed by systemic administration (i.v.) of 70-kD FITC-dextran and leakage was assessed 30 min later. Representative images of three separate experiments using three to four mice/genotype each time. Bar, $100 \mu \mathrm{m}$. (E) Quantification of FITC-dextran extravasation by determination of fluorescence in the tissues shown in C. $n=4$ mice/genotype from 1 representative experiment. ${ }^{*} \mathrm{P}<0.05 i^{* *}, \mathrm{P}<0.01$. 

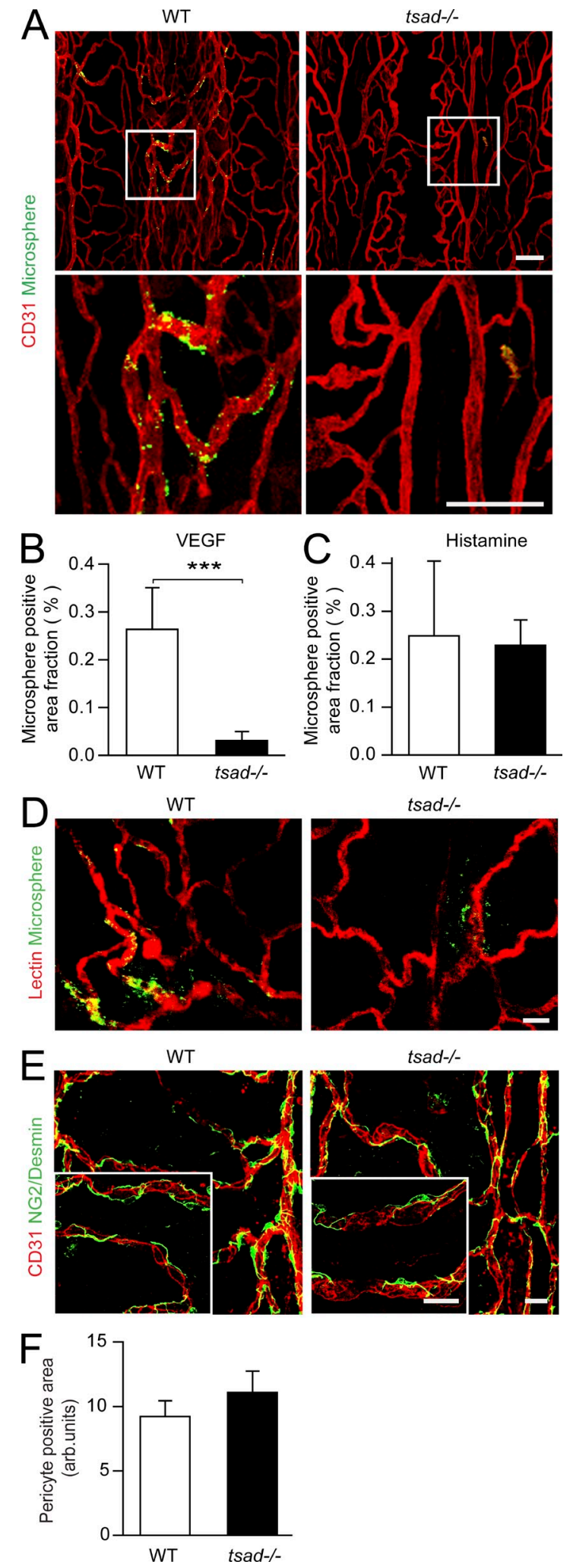

Figure 3. Impaired VEGF-induced FITC microsphere extravasation in $\mathrm{tsad}^{-/-}$trachea in the presence of flow and intact pericyte coating. (A) WT and $t^{5} \mathrm{~d}^{-1-}$ mice were injected (i.v.) with $30 \mathrm{~nm}$ fluorophore-coupled microspheres (green) combined with saline (not depicted) or VEGF. 30 min later, whole-mount preparations of trachea were immunostained with of the cytoplasmic tyrosine kinase Lck (Granum et al., 2006). We used GST-c-Src-SH3 as a probe to test binding to TSAd proline-rich peptides (Fig. $1 \mathrm{~B}$ ), which showed strong binding of c-Src-SH3 to several stretches in TSAd, including the proline-rich region around P247 and P271. Based on these data, we propose that TSAd binds to VEGFR2 at Y951 and that TSAd in turn presents several binding sites for the SH2 and SH3 domain of $\mathrm{c}-\mathrm{Src}$ (see Fig. $1 \mathrm{C}$ for a schematic outline).

\section{Vascular permeability is impaired in TSAd-deficient mice}

Because c-Src has been implicated in the regulation of vascular permeability (Weis and Cheresh, 2005), we analyzed $t_{s a d^{-1-}}$ mice, which are fertile and apparently healthy, for their ability to respond to VEGF in a classical Miles assay. Evans blue was administered by tail vein injection in mice that received an intradermal bolus of $100 \mathrm{ng}$ VEGF or vehicle on the back (Fig. 2 A). Permeability was induced by VEGF in WT mice, but there was a significant decrease in VEGF-induced Evans blue extravasation in $t s a d^{-1-}$ skin (Fig. 2 B). There was no change in basal leakage of Evans blue in the kidney, lung, or skin, between WT and $t s a d^{-/-}$ mice (Fig. 2 C).

We furthermore observed a considerable decrease in VEGF-induced extravasation of systemically delivered FITCdextran in $t_{s} d^{-1-}$ mice (Fig. $2 \mathrm{D}$ ). There was less than a twofold induction of FITC-dextran extravasation with VEGF in the $t s a d^{-/-}$skin, compared with a sixfold induction in the WT skin (Fig. 2 E). Basal permeability in the absence of VEGF was not affected by TSAd deficiency in this assay (unpublished data).

VEGF also induced extravasation of fluorophore-labeled microspheres from venules in the WT, but not the $t s a d^{-1-}$ trachea (Fig. 3 A; see Fig. 3 B for quantification). In contrast, histamine-induced extravasation was comparable in the WT and $t s a d^{-1-}$ trachea (Fig. $3 \mathrm{C}$ ), and the tracheal vasculature was similarly perfused in the two genotypes (Fig. 3 D). Similarly, the mean arterial blood pressure, blood flow, blood gases, and acid-base balance were not altered in $t_{s} a d^{-/-}$mice compared with WT mice (Table 1). There was also no

anti-CD31 (red). Bottom panels show magnification of boxed area in top panels. Representative images are shown of three separate experiments using three to four mice/genotype each time. Bars, $100 \mu \mathrm{m}$. (B) Quantification of data in A. $n=4$ mice/genotype from 1 of 3 experiments. ${ }^{* *}, P<0.001$. (C) Quantification of histamine-induced extravasation of microspheres in WT and tsad ${ }^{-/-}$trachea. $n=4$ mice/genotype from 1 of 3 experiments. (D) WT and $t s a d^{-1-}$ mice were injected (i.v.) with DyLight 594 lectin (red), microspheres (green), and VEGF. 30 min later, whole-mount preparations of trachea were prepared and assessed by confocal imaging. Representative images are shown of two separate experiments using three mice/genotype each time. Bar, $20 \mu \mathrm{m}$.

(E) Immunofluorescent staining with antibodies for NG2/desmin and CD31. Representative results of two separate experiments using three mice/genotype each time. Bar, $20 \mu \mathrm{m}$. (F) Quantification of data from one experiment as shown in E. $n=3$ mice/genotype. 
change in pericyte coating or pericyte morphology in the $t_{s a d}{ }^{-1-}$ vasculature (Fig. 3, E and F). We conclude that TSAd deficiency selectively attenuated VEGF-induced vascular permeability without disturbing blood flow, blood pressure, or pericyte support of the vessels.

\section{VEGF-induced c-Src activation in vitro depends on TSAd}

We next investigated how TSAd contributes to VEGF-induced c-Src activation using primary endothelial cells. We used nanofluidic isoelectric focusing (NanoPro), which allows antibody-mediated detection of protein expression and posttranslational modifications in a highly sensitive manner. Cell lysates from human dermal microvascular endothelial cells (HDMECs) treated with or without VEGF for $7 \mathrm{~min}$ were analyzed for c-Src pY418 reactivity. As shown in Fig. 4 A, untreated cells contained one major peak in the electropherogram, corresponding to c-Src phosphorylated at Y418 in an adhesion-dependent manner (peak 1, P1). VEGF treatment resulted in an increase in P1 area (Fig. 4 B) and the appearance of a second peak (P2), both of which were sensitive to lambda phosphatase digestion (bottom). The more acidic isoelectric point ( $\mathrm{pI}$ ) of the $\mathrm{P} 2$ pool indicates that apart from being phosphorylated at Y418, this fraction of c-Src is phosphorylated at additional residues.

Analysis for pY527 reactivity showed one major peak (P3) in untreated cells, corresponding to pY527-modified, inactive c-Src. Treatment with VEGF led to the enhancement of a P4 peak and, interestingly, a reduction in the P3 peak area (Fig. 4 B). P3 most likely corresponds to c-Src phosphorylated at Y527, whereas P4 is phosphorylated at Y527 and likely at another residue that is distinct from that in the pY418-reactive P2. Both P3 and P4 were removed with phosphatase treatment. However, the anti-pY527 antibody still detected phosphatasetreated protein, possibly from epitopes unmasked by the phosphatase digestion. Analysis for c-Src protein antibody reactivity showed a pattern very similar to that of pY527. It is notable

Table 1. Blood flow, gases, and $\mathrm{pH}$

\begin{tabular}{|c|c|c|}
\hline Strain & WT $(n=8)$ & $t_{s a d} /-(n=11)$ \\
\hline & mean \pm SEM & mean \pm SEM \\
\hline Mean arterial blood pressure $(\mathrm{mmHg})$ & $85 \pm 2$ & $85 \pm 5$ \\
\hline \multicolumn{3}{|l|}{ Blood flow $(\mathrm{ml} / \mathrm{min} \mathrm{g})$} \\
\hline Pancreas caput & $1.64 \pm 0.34$ & $2.52 \pm 0.33$ \\
\hline Pancreas cauda & $1.38 \pm 0.27$ & $1.17 \pm 0.27$ \\
\hline Duodenum & $3.19 \pm 0.60$ & $4.50 \pm 0.96$ \\
\hline Colon & $2.34 \pm 0.33$ & $1.11 \pm 0.28$ \\
\hline Liver (hepatic artery) & $0.02 \pm 0.01$ & $0.10 \pm 0.03$ \\
\hline Kidneys & $4.38 \pm 0.90$ & $4.40 \pm 1.07$ \\
\hline Adrenal glands & $17.57 \pm 4.26$ & $18.59 \pm 4.95$ \\
\hline Cerebrum & $0.74 \pm 0.11$ & $1.49 \pm 0.46$ \\
\hline White adipose tissue & $0.05 \pm 0.01$ & $0.01 \pm 0.001$ \\
\hline Lungs (= shunted blood) & $0.07 \pm 0.04$ & $0.04 \pm 0.01$ \\
\hline \multicolumn{3}{|l|}{ Blood gases and $\mathrm{pH}^{\mathrm{a}}$} \\
\hline Blood pH & $7.25 \pm 0.03$ & $7.28 \pm 0.04$ \\
\hline $\mathrm{PCO}_{2}(\mathrm{kPa})$ & $6.37 \pm 0.32$ & $5.06 \pm 0.62$ \\
\hline Total $\mathrm{CO}_{2}(\mathrm{mmol} / \mathrm{l})$ & $22.6 \pm 1.2$ & $19.0 \pm 1.9$ \\
\hline $\mathrm{PO}_{2}(\mathrm{kPa})$ & $13.75 \pm 0.46$ & $11.85 \pm 0.98$ \\
\hline Oxygen saturation (\%) & $96.2 \pm 0.9$ & $94.1 \pm 1.0$ \\
\hline $\mathrm{S}-\mathrm{HCO}_{3}{ }^{-}(\mathrm{mmol} / \mathrm{l})$ & $21.0 \pm 1.2$ & $17.8 \pm 1.6$ \\
\hline $\mathrm{S}-\mathrm{Na}^{+}(\mathrm{mmol} / \mathrm{l})$ & $144 \pm 1$ & $147 \pm 1.0$ \\
\hline $\mathrm{S}-\mathrm{K}^{+}(\mathrm{mmol} / \mathrm{l})$ & $5.6 \pm 0.2$ & $4.7 \pm 0.2$ \\
\hline Base excess (mmol/l) & $-6 \pm 2$ & $-8 \pm 1.0$ \\
\hline Hemoglobin (g/liter) & $116 \pm 4$ & $112 \pm 5$ \\
\hline
\end{tabular}

a Both strains demonstrated slight anesthesia-induced hyperventilation (high $\mathrm{PO}_{2}$, low $\mathrm{PCO}_{2}$, low base excess, and low total $\mathrm{CO}_{2}$ ). There were no significant differences between the groups. 

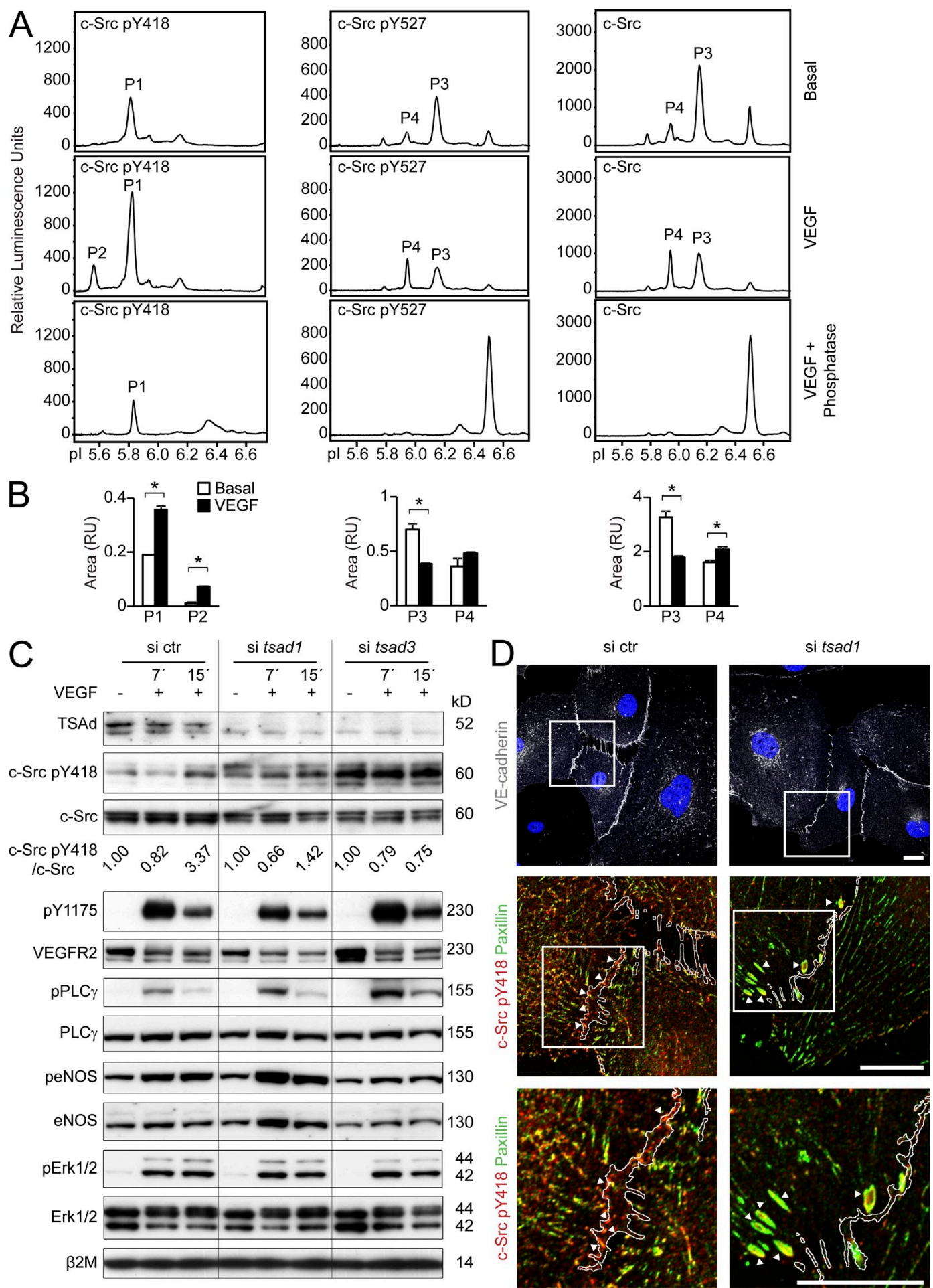

Figure 4. VEGF-induced activation of Src and the effect of tsad silencing. (A) NanoPro analysis of c-Src posttranslational modification in HDMECS was performed on cells treated with vehicle (basal) cells or with VEGF for $7 \mathrm{~min}$. Cell lysates were subject to capillary isoelectric focusing and probing with anti-c-Src pY418, anti-c-Src pY527, and anti-c-Src protein antibodies. Peaks (P) identified by antibody-binding, followed by enhanced chemiluminescence are indicated. Bottom panels show antibody detection of c-Src protein after phosphatase treatment. Representative results of three independent experiments are shown. (B) Quantification of one experiment as shown in A. (C) HDMECs were transfected with control siRNA (si ctr) or different tsad siRNAS followed by stimulation with VEGF for 7 or 15 min. Blotting was performed on total lysates with antibodies against TSAd; phosphorylated proteins c-Src pY418, pY1175 (autophosphorylation site in VEGFR2), pPLC $\gamma$, peNOS, pERK1/2; and against the corresponding total protein pools. Molecular weights in kilodaltons (kD) are indicated to the right. Immunoblotting for $\beta 2$ microglobulin was used as a control for equal loading. All results are from the same set of extracts run out on 

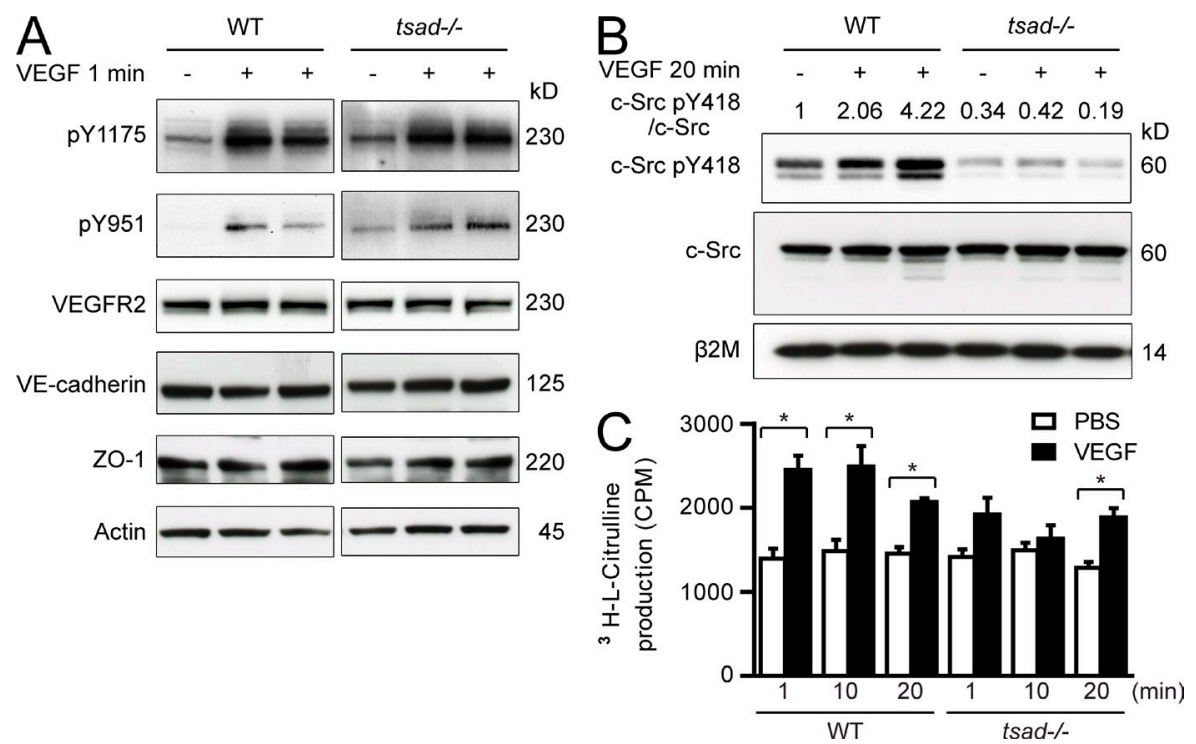

Figure 5. TSAd deficiency attenuates phosphorylation of Src but not VEGFR2 and eNOS pathways in vivo. (A) WT and tsad $^{-1-}$ mice were injected (i.v.) with VEGF and lungs were harvested 1 min later. Blotting was performed on total lung lysates using antibodies against VEGFR2 phosphorylation sites pY1175 and pY951, VEGFR2 protein, VE-cadherin and ZO-1. Control for equal loading was done by immunoblotting for actin. Molecular weights in kilodaltons (kD) are indicated to the right. Data are shown for one mouse injected with PBS and two mice injected with VEGF. Representative results of at least three independent experiments. $n=3$ mice/genotype. (B) Mice were treated as in $A$, but lungs were harvested after 20 min after injection (i.v.) of PBS or VEGF. Blotting was performed on total lung lysates using antibodies against c-Src pY418 and c-Src protein. Immunoblotting for $\beta 2$ microglobulin ( $\beta 2 \mathrm{M})$

was performed to control for equal loading. Molecular weights in kilodaltons (KD) are indicated to the right. Numbers above lanes indicate fold-change in c-Src pY418/ total c-Src protein, set to 1 for the unstimulated WT sample. Representative results of three separate experiments are shown. (C) WT and tsad ${ }^{-1-}$ mice were injected (i.v.) with PBS or VEGF, and lungs were harvested 1, 10, and 20 min later. Conversion of L-arginine to nitric oxide (NO) in lung tissue was determined using stoichiometric production of $\mathrm{L}$-citrulline. ${ }^{*}, \mathrm{P}<0.05 . n=3$ mice/genotype for each time point from 1 experiment.

that $\mathrm{P} 1$, corresponding to $\mathrm{pY} 418$, was not detected by the $\mathrm{c}-\mathrm{Src}$ protein antibody, indicating that the c-Src pY418 pool is a minor fraction of the total pool.

Combined, these data show that VEGF induces phosphorylation of the activating Y418 residue, located on the c-Src kinase activation loop, but that VEGF also promotes decreased phosphorylation of the negative regulatory Y527. In addition, VEGF induces additional posttranslational modifications, most likely phosphorylation of tyrosine, serine, or threonine residues of c-Src at several sites, resulting in P2 and P4 in Fig. 4 A.

We examined the effect of tsad siRNA-mediated silencing in HDMECs. WhereasVEGF induced a threefold increase in c-Src activation (in relation to total Src protein pool) in control siRNA-transfected cells, silencing of tsad using two different tsad siRNAs perturbed c-Src activation, which increased only marginally or not at all with VEGF treatment (Fig. 4 C). However, the basal level of c-Src p418 was elevated in the tsad siRNA-treated cells relative to control siRNA-treated cells. In contrast, tsad siRNA did not affect VEGF-induced VEGFR2 phosphorylation at pY1175 or phosphorylation of PLC $\gamma$, ERK1/2, or endothelial nitric oxide synthase (eNOS). Akt was not induced in the HDMECs under the conditions used here irrespective of transfection of siRNA (unpublished data). Similar data were obtained when analyzingVEGF-induced signaling in human umbilical vein endothelial cells that were transfected or not with tsad siRNA (unpublished data).

Immunofluorescent staining for $\mathrm{c}-\mathrm{Src} \mathrm{pY} 418$ on HDMECs (Fig. 4 D) showed colocalization of activated c-Src with VE-cadherin-positive adherens junctions of endothelial cells (Fig. 4 D) and with paxillin in focal adhesions. Importantly, tsad siRNA silencing attenuated detection of c-Src pY418 associated with adherens junctions in control siRNAtransfected cells. In contrast, c-Src pY418 was still present in large focal adhesions (Fig. 4 D, arrowheads) in the tsad siRNAtransfected cells.

\section{VEGF-induced Src activation in vivo depends on TSAd}

To validate the role for TSAd in VEGF-induced c-Src activation in vivo, we studied activation of VEGFR 2 and c-Src in WT and $t s a d^{-1-}$ mice after systemic delivery of VEGF through tail vein injection. Lungs, which contain $\sim 50 \%$ endothelial cells, were harvested at different time points after VEGF injection and analyzed by immunoblotting, as shown in Fig. 5 A. VEGF injection allowed very rapid phosphorylation of VEGFR2 at Y949 and Y1173 (corresponding to Y951 and Y1175 in the human VEGFR2) in WT as well as $\mathrm{tsad}^{-/-}$mice. There was no difference in expression levels

different gels to optimize separation. Numbers under total c-Src bands indicate fold change in c-Src pY418/total c-Src protein in the different conditions; the c-Src pY418/total c-Src ratio in the unstimulated ctr-siRNA/ sample was set to 1. Representative results of at least three independent experiments are shown. (D) Immunofluorescent staining for VE-cadherin (white), c-Src pY418 (red), and paxillin (green) of HDMEC cultures transfected with control siRNA (si ctr) or tsad siRNA1 (si tsad) followed by stimulation with VEGF for $7 \mathrm{~min}$. Bottom panels show magnification of merged images from boxed regions in the middle row of panels. White line outlines VE-cadherin-positive junctions, arrowheads indicate c-Src p418 localized at adherens junctions in control siRNA cells and in focal adhesions in tsad siRNA cells.. Representative results of at least three independent experiments are shown. Bar, $20 \mu \mathrm{m}$. 
of VEGFR2 or the adherens and tight junction proteins VE-cadherin and ZO-1, respectively, between WT and $t_{s a d^{-/-}}$samples. Importantly, only WT, but not $t s a d^{-/-}$, lung samples contained higher levels of c-Src pY418 at $20 \mathrm{~min}$ after delivery of VEGF to the circulation (Fig. 5 B). Indeed, even the basal level of c-Src activity was decreased in the tsad $^{-/-}$lung samples.

We further analyzed the consequence of tsad knockout by measuring accumulation of ${ }^{3}[\mathrm{H}]$-citrulline, an eNOS metabolite (Feng et al., 2010). Lungs from WT mice harvested after tail vein injection of VEGF showed significant accumulation of ${ }^{3}[\mathrm{H}]$-citrulline. In the $t_{s} a^{-/-}$mouse lungs, accumulation of ${ }^{3}[\mathrm{H}]$-citrulline still occurred, but with slower kinetics and to a reduced extent compared with WT (Fig. 5 C).

\section{Persistent endothelial cell junctions in isolated primary tsad $^{-/-}$endothelial cells}

To show the consequence of TSAd deficiency on adherens junctions, endothelial cells isolated from mouse lungs were treated with VEGF and immunostained for VE-cadherin (Fig. $6 \mathrm{~A}$ ). WT endothelial cells displayed a relatively continuous VE-cadherin-positive junctional lining, which was disrupted and rearranged in response to VEGF (see Fig. 6 B for quantification ofVE-cadherin area under different conditions). The rearrangement of VE-cadherin was at least in part dependent on $\mathrm{c}-\mathrm{Src}$, as treatment with a c-Src kinase inhibitor decreased the VE-cadherin-positive area in the VEGF-treated WT endothelial cells. In contrast, tsad $^{-/-}$ endothelial cells revealed no or very limited changes in VE-cadherin morphology and there was no change in VEcadherin area with and without VEGF (Fig. 6 B). Similar results were obtained when analyzing adherens and tight junctions in endothelial cells isolated from WT and $t s a d^{-1-}$ livers (unpublished data).

To show the localization of c-Src pY418 in relation to junctions in the presence and absence of TSAd, we used purified lung-derived endothelial cells treated or not with VEGF, followed by immunostaining for c-Src pY418 and for VEcadherin. In the basal condition, c-Src pY418 was localized in the cell periphery. VEGF treatment induced translocation of active c-Src into VE-cadherin-positive adherens junctions. In contrast, in the $t_{s a d^{-1-}}$ endothelial cells, the c-Src pY418 immunostaining was similarly localized in the presence and absence ofVEGF (Fig. 6 C). Combined, these data show that TSAd is required for VEGF-induced c-Src activation in endothelial cell junctions. The underlying mechanism involves complex formation between VE-cadherin and TSAd, together with VEGFR2 and c-Src, which was observed in WT but not in $t s a d^{-/-}$lung lysates (Fig. 6 D).

TSAd-dependent regulation of endothelial junctions in vivo We further studied VE-cadherin-positive junctions in vivo, in whole-mounts of the mouse cremaster muscle (Fig. 7 A). Treatment of this very thin and accessible muscle with VEGF through superfusion for $30 \mathrm{~min}$ caused rearrangement of VE-cadherin-positive junctions in the WT venules. In contrast,
VE-cadherin immunostaining remained uninterrupted in the $t_{s a d^{-1-}}$ cremaster muscle vessels with VEGF treatment (Fig. 7 A). Image analysis and quantification (Fig. 7 B) showed that the junctional outline moved further away from the junction midline in the VEGF-treated WT vessels, whereas VEGF-treated $t s a d^{-/-}$junctions remain unaffected compared with basal. The VEGF-induced change in VE-cadherin morphology was statistically significant (Student's $t$ test; WT vs. basal, $\mathrm{P}<0.013)$. These data are in accordance with the pattern observed in the isolated endothelial cells from WT and $t_{s a d}{ }^{-/-}$lungs (Fig. $6 \mathrm{~A}$ ).

\section{DISCUSSION}

We show that TSAd deficiency is accompanied by loss of VEGF-induced c-Src activation in vitro and in vivo. This is paralleled by an arrest in VEGF-induced vascular permeability, as indicated by the markedly reduced extravasation of Evans blue, $70-\mathrm{kD}$ dextran, and 30-nm microspheres in the mouse skin and trachea. The vascular permeability arrest appears to be specific to VEGF and does not affect histamineinduced extravasation. There is also no disturbance in blood flow or blood pressure. TSAd exerts its effect by binding to VE-cadherin, VEGFR2, and c-Src in endothelial junctions. These data provide for the first time a mechanism for how VEGFR2-dependent permeability is regulated on the molecular level.

Altered vascular permeability is perhaps one of the most significant effects of VEGF, in accordance with its alternative designation VPF (Senger et al., 1983). Two principal pathways for vascular permeability have been suggested. One involves VEGF-induced formation of caveolae and the assembly of caveolae into VVOs, thus allowing trans-endothelial passage (Baluk et al., 1997; Dvorak and Feng, 2001). VVOdeficient mouse models are not available and the molecular regulation of VVOs by VEGF remains to be deduced. However, caveolin-1-deficient mice show increased VEGFR2 tyrosine phosphorylation and enhanced vascular permeability (Lin et al., 2007). A second mechanism for VEGF-regulated vascular permeability involves transient dissolution of adherens junctions in a VE-cadherin-dependent manner (Weis and Cheresh, 2005). VEGF induces tyrosine phosphorylation of VE-cadherin and its binding partners $\beta$-catenin, plakoglobin, and p120 in vitro (Esser et al., 1998) and in vivo (Weis et al., 2004a; Lambeng et al., 2005). The effect of VEGF is mediated by the cytoplasmic tyrosine kinases Src and Yes (Eliceiri et al., 1999). Thus, VEGF-induced c-Src activation has been implicated in the disruption of molecular complexes involving VEGFR2 and VE-cadherin/ $\beta$-catenin that lead to destabilization of junctions (Weis et al., 2004a,b) directly through c-Src-mediated tyrosine phosphorylation of VEcadherin at Y658 (Wallez et al., 2007). Activation of focal adhesion kinase in response to VEGF and downstream tyrosine phosphorylation of $\beta$-catenin are additional prerequisites for opening of paracellular junctions (Chen et al., 2012).

Junction-dependent permeability may also be regulated through the internalization of $\mathrm{VE}$-cadherin, a process 

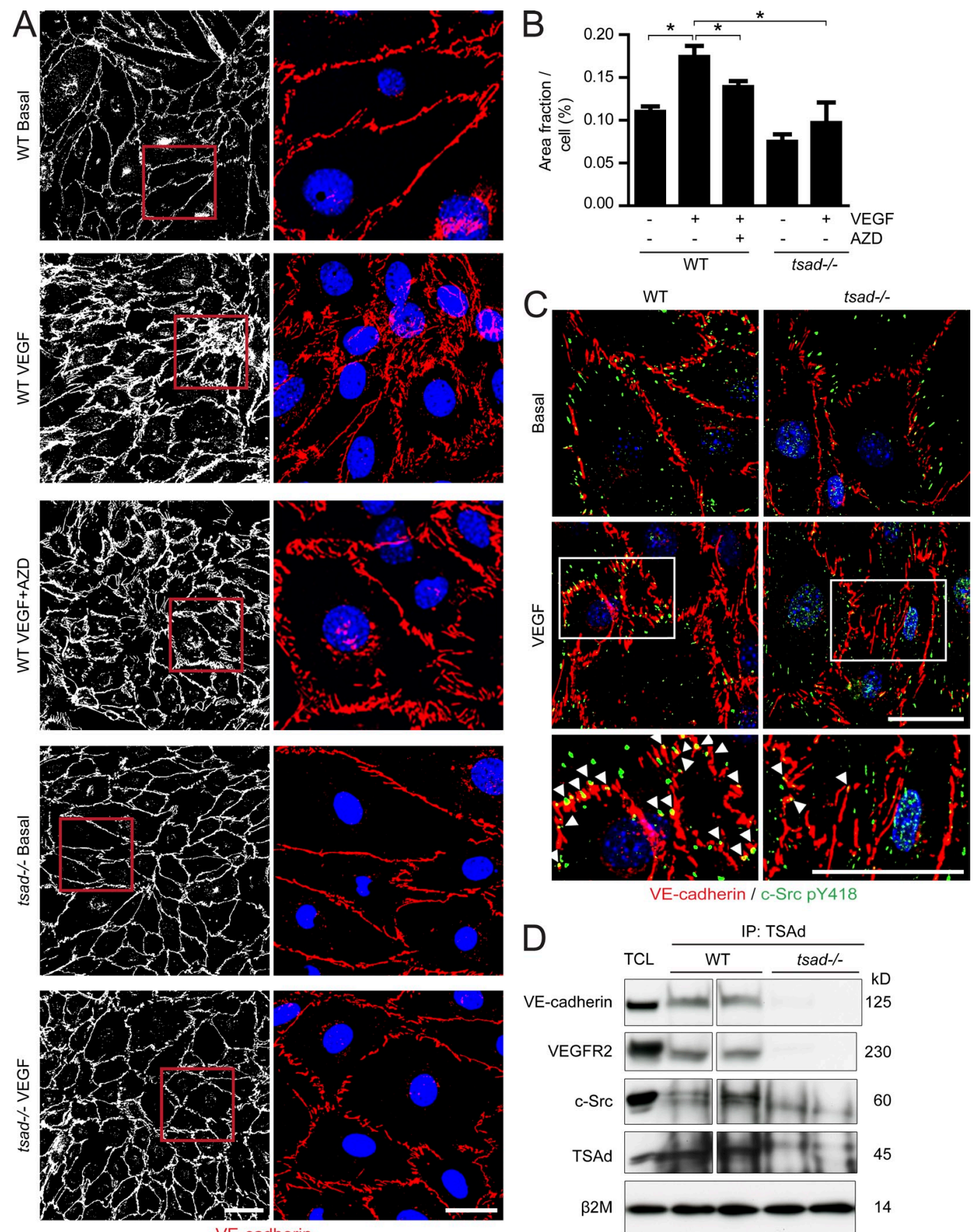

VE-cadherin / c-Src pY418
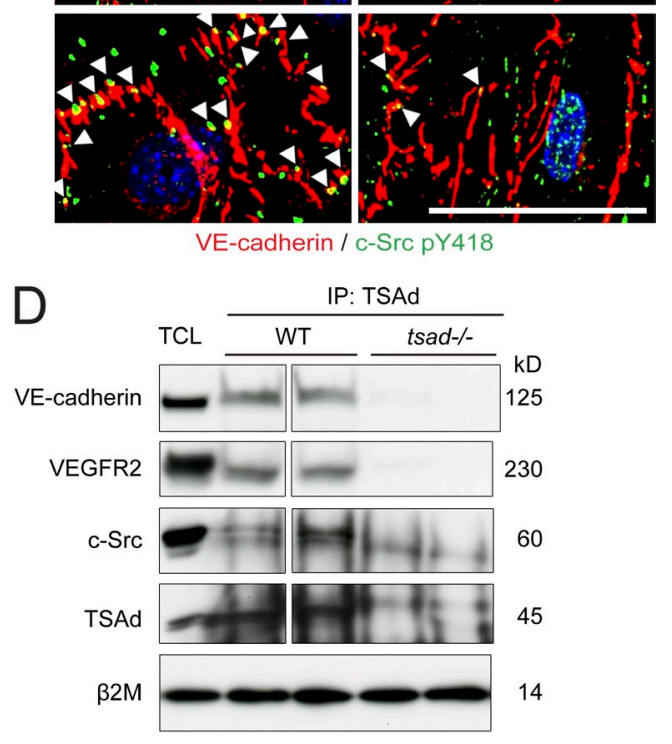

Figure 6. Persistent adherens junctions in VEGF-stimulated isolated $t_{s a d^{-/-}}$endothelial cells. (A) Primary endothelial cells isolated from WT or $t_{s a d^{-1}}$ mouse lungs were cultured until confluent, and then treated for $10 \mathrm{~min}$ with vehicle or VEGF (100 $\left.\mathrm{ng} / \mathrm{ml}\right)$ with or without the Src kinase inhibitor AZD0530 (AZD; $10 \mu \mathrm{M}$ ). Cells were fixed and immunostained for VE-cadherin (left, white; right, red) and Hoechst 33342 (right, blue) to visualize adherens junctions and nuclei, respectively. Representative results from four separate cell isolations are shown. Bars, $50 \mu \mathrm{m}$ (left row) and $20 \mu \mathrm{m}$ (right row).

(B) Quantification of VE-cadherin immunostaining in A, as VE-cadherin-positive area per cell, on $4 \times 300$ cells/genotype; 4 separate cell isolates.

(C) Immunostaining for VE-cadherin (red) and c-Src pY418 (green) on isolated lung endothelial cells from WT and tsad ${ }^{-1-}$ mice and treatment of confluent cultures for $10 \mathrm{~min}$ with $100 \mathrm{ng} / \mathrm{ml}$ VEGF. Bottom panels show magnification of boxed region in images from VEGF-treated samples. Arrowheads indicate c-Src pY418 localized in adherens junctions. Representative results from three separate experiments are shown. Bar, 20 um. (D) Immunoprecipitation (IP) from lysates of WT and tsad ${ }^{-1-}$ lung tissue using an anti-TSAd antibody, followed by immunoblotting for VE-cadherin, VEGFR2, and total c-Src protein. Total cell lysate (TCL) was used as a control to identify proteins in the IP and to control for equal protein concentration by immunoblotting for $\beta 2$ microglobulin $(\beta 2 \mathrm{~m})$. Molecular weights in kilodaltons $(\mathrm{kD})$ are indicated to the right. Data are representative of two independent experiments. $n=2$ mice/genotype. Spacer line separates two parts of the same gel/blot, after excision of marker lane. 

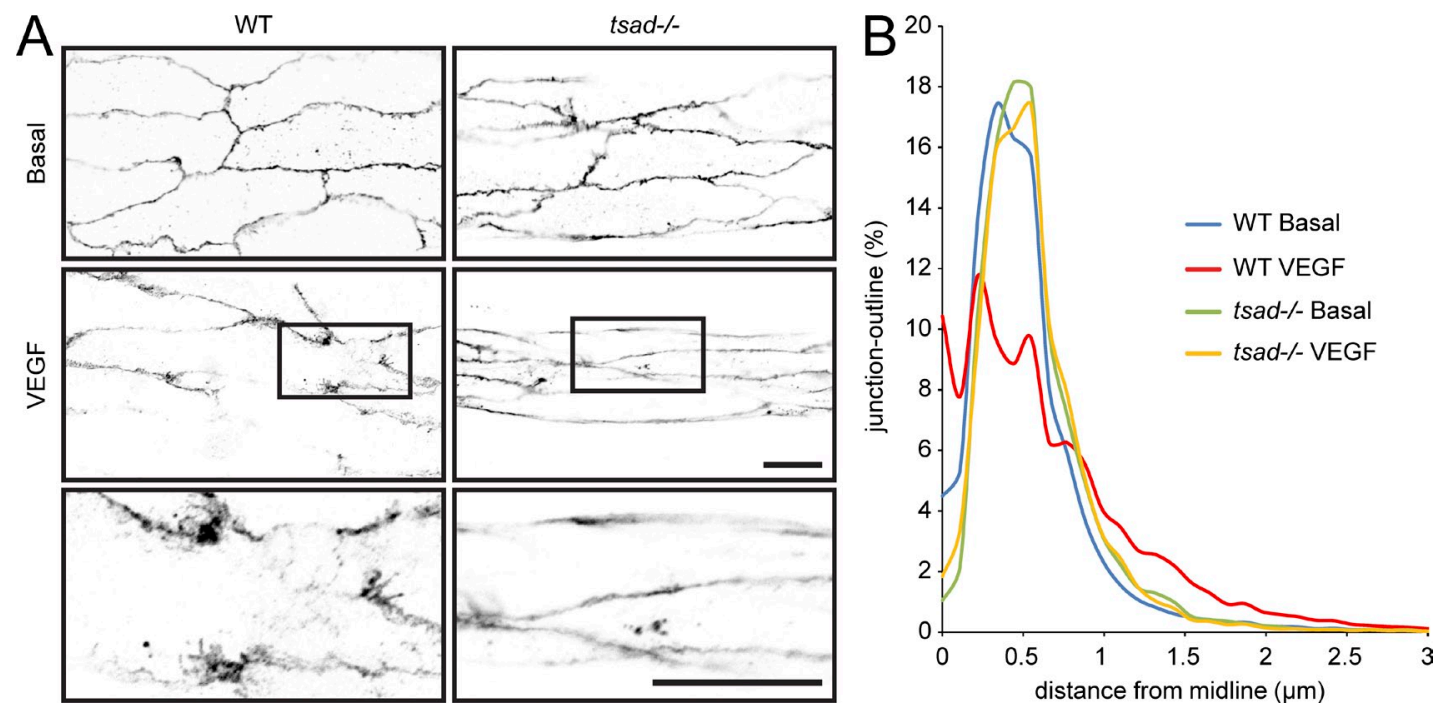

Figure 7. TSAd regulates adherens junctions in vivo. (A) Cremaster muscles superfused for 30 min with vehicle (top) or with $100 \mathrm{ng} / \mathrm{ml}$ VEGF (middle), followed by whole-mount immunostaining with anti-VE-cadherin. Bottom panels show higher magnification of boxed region in middle panels. Representative images are shown. $n=6$ WT mice and $4 \mathrm{tsad}^{-{ }^{-}}$mice each for the basal and VEGF treatment conditions; a total of 20 mice. Each superfusion was performed independently. Images were inverted and linearly contrast stretched by 20\%. Bars, $50 \mu \mathrm{m}$. (B) Percentage of junction outline localized at different distances from junction midline as defined by VE-cadherin immunostaining in cremaster muscles superfused with VEGF, as in A, for WT basal (blue), WT treated with VEGF (red), tsad ${ }^{-/-}$basal (green), and $t s a d^{-1-}$ treated with VEGF (yellow). $n=6$ WT mice for each condition and 4 tsad ${ }^{-1-}$ mice for each condition.

that can occur in a clathrin-dependent manner (Xiao et al., 2005). Moreover, c-Src-dependent activation of Vav and p21-activated kinase (PAK) leads to serine phosphorylation of VE-cadherin at S665 (Gavard and Gutkind, 2006) and internalization of VE-cadherin. VE-cadherin immunostaining in endothelial cell cultures in vitro (Fig. 6) and vessels in vivo (Fig. 7) show rearrangement of adherens junctions in response to VEGF in the WT, but not in the $t s a d^{-1-}$ condition. Whether the VEGF-induced effect in the WT cells was accompanied by VE-cadherin internalization was not addressed.

The response to histamine in extravasation of fluorescent micropheres was not impaired in $t s a d^{-/-}$mice (Fig. 3 C), which is in agreement with previous data showing that Src activity is dispensable for histamine-induced vascular permeability (Eliceiri et al., 1999). This indicates that junctions are not generally affected by the loss of TSAd expression. We lack reagents to perform immunostaining for TSAd on mouse tissues. However, in lysates from WT lungs, which contain 50\% endothelial cells, we could show that TSAd exists in complex with VE-cadherin,VEGFR2, and c-Src, and thus that TSAd is at least partially localized in junctions. We have shown before that TSAd engages in transient complex formation with both VEGFR2 and c-Src. TSAd's SH2 domain binds directly to VEGFR2 phosphorylation sites, and the Pro-rich domain binds to c-Src (Fig. 1). It is possible that the TSAd-VEcadherin interaction is indirect and dependent on VEGFR2, which is complexed to VE-cadherin (Tzima et al., 2005). Collectively, these data reinforce a critical role for TSAd in regulation of vascular permeability.
Activation of eNOS and enhanced NO release by different inflammatory stimuli, includingVEGF, has been shown to lead to increased microvascular permeability (Sessa, 2009). Thus, VEGF fails to induce vascular permeability in eNOS knockout mice (Fukumura et al., 2001). Activation of eNOS in response to VEGF and histamine has been shown to involve PLC $\gamma$ and subsequent activation of protein kinase C, as well as AKT/protein kinase B (PKB; Fulton et al., 1999; Fukumura et al., 2001; Di Lorenzo et al., 2009). TSAd has been reported to couple to PLC $\gamma$ and PI3K-regulated pathways in endothelial cells (Wu et al., 2000). We previously showed that VEGF still induced activation of PLC $\gamma$ and PI3K/Akt in cells expressing a mutated Y951F VEGFR2, i.e., in the absence of engagement of TSAd (Matsumoto et al., 2005). Our data are in accordance with studies by Shibuya and coworkers demonstrating that Y1175 but not Y951 in VEGFR2 is required for binding and activation of PLC $\gamma$ (Takahashi et al., 2001). Activation of eNOS involves phosphorylation on at least six residues: serine, threonine, and tyrosine (Durán et al., 2010). The fact that acetylcholine induces the same pattern of eNOS phosphorylation asVEGF but still fails to induce permeability strongly indicates that phosphorylation is not sufficient to mediate full eNOS activation. Indeed, additional events, such as translocation of eNOS from the membrane to the cytosol are required for eNOS-mediated permeability (Durán et al., 2010). The intact VEGF-induced eNOS phosphorylation in tsad siRNA-transfected cells (Fig. 2 A), but partial accumulation of ${ }^{3}[\mathrm{H}]$-citrulline in $t_{\text {sad }}{ }^{-1-}$ lungs (Fig. $5 \mathrm{C}$ ), is compatible in that initial steps in the eNOS-NO-permeability pathway are operating in the absence of TSAd. 
Several VEGFR2-coupled pathways have been implicated in c-Src activation, including the scaffold protein GAB-1, which was implicated in most if not all pathways induced by VEGF (Laramée et al., 2007). Endothelialspecific knockout of GAB-1 is compatible with developmental angiogenesis, but leads to impaired ischemia-induced adult angiogenesis and increased apoptosis of endothelial cells due to loss of hepatocyte-growth factor signaling (Zhao et al., 2011). Furthermore, VEGF-activation of Akt and eNOS are impaired in GAB-1 knockout endothelial mice (Lu et al., 2011). GAB-1 deficiency therefore appears to affect signaling in a more general way than TSAd deficiency, by disturbing a wider spectrum of endothelial biology in response to several input stimuli. Moreover, Meyer et al. (2008) showed that c-Src binds to VEGFR2 at Y1057 (Y1059 in the human VEGFR2), which is located on the kinase activation loop. It is expected that binding of signaling molecules to the activation loop would disturb kinase activation. We have not been able to address the role of Y1057/1059 in c-Src activation as an Y1059F mutant of VEGFR2 is an inactive kinase in our hands (Matsumoto et al., 2005). Furthermore, the phosphopeptide dot blot analysis in the current study (Fig. 1 A) showed binding of c-Src SH2 to Y1054, but not to Y1059. We do not formally exclude the potential contribution of these VEGFR2 residues in c-Src activation, but believe that their primary role is in regulation ofVEGFR2 kinase activity. c-Src activation by VEGF in primary endothelial cells involved both increased phosphorylation at the positively regulating Y 418 and dephosphorylation at the negatively regulating Y527 (Fig. 1 B). In agreement, a dominant-negative C-terminal Src kinase (CSK), which prevents phosphorylation of c-Src at Y527 by WT CSK, promotesVE-cadherin phosphorylation at Y658, 685, and 731 (Adam et al., 2010). We also noted that VEGF induces additional posttranslational modifications of c-Src; possibly phosphorylation as judged from the more acidic $\mathrm{pI}$ of the modified c-Src. In accordance, other growth stimuli, such as PDGF, have been shown to induce additional phosphorylation to Y418 and Y527 in c-Src (Roskoski, 2005). The role of these additional sites remains to be shown.

We conclude that TSAd is essential for VEGF-induced c-Src activation and translocation to endothelial junctions, and for subsequent regulation of vascular permeability. Importantly, our data suggest that TSAd may be a useful drug target for the specific modulation of excess VEGF-induced permeability in pathological conditions.

\section{MATERIALS AND METHODS}

Antibodies, recombinant proteins, and growth factors. The following antibodies were used: rabbit anti-desmin and $\beta 2$ microglobulin (Abcam); rat anti-mouse CD31 and mouse anti-eNOS pS1177 (BD); phospho-VEGFR2 (Tyr1175), phospho-VEGFR2 (TyrY951), and phospho-p44/42 (Tyr202/ Tyr204; Cell Signaling Technology); rabbit anti-phospho c-Src (Tyr418), TRITC-conjugated phalloidin, and rabbit anti-ZO-1 (Invitrogen); goat anti-Armenian hamster Cy3 (Jackson ImmunoResearch); rabbit anti-NG2
(Millipore); sheep anti-human TSAd, goat anti-mouse VEGFR2, and goat anti-mouse VE-Cadherin (R\&D Systems); goat anti-human VE-cadherin, goat anti- $\beta$-actin, rabbit anti-c-Src, rabbit anti-paxillin, and mouse antiPLC $\gamma$ (Santa Cruz Biotechnology, Inc.); Armenian hamster anti-mouse CD31 clone 2H8 (Thermo Fischer Scientific). Dylight 594 lectin was obtained from Vector Laboratories. Fluorescently labeled second antibodies were derived from donkey (Invitrogen).

TSAd-SH2 was amplified by PCR from an intact cDNA clone (Granum et al., 2006) and cloned into the BamHI-NotI pGEX-6P-1 (GE Healthcare). Src-SH2 cloned into pGEX-2T was a gift from J.T. Parsons (University of Virginia, Charlottesville,VA; Flynn et al., 1993). GST-SH2 domain constructs were expressed in Escherichia coli BL21 (DE3) and GST-fusion protein produced according to the description by the manufacturer of the vector. Fusion protein was purified by Glutathione Sepharose 4B beads (GE Healthcare) in a batch mode as described by the manufacturer. GST-SH2 domains were eluted from beads using glutathione, and protein concentration was measured by NanoDrop spectrophotometry (Thermo Fischer Scientific) at $\lambda 280$ and a theoretically obtained extinction coefficient (ProtParam). Recombinant mouse VEGF-A165 was purchased from PeproTech.

TSAd nomenclature and mouse model. TSAd is also known as Lckassociated adapter protein (LAD; Choi et al., 1999), Rlk/Itk binding protein (Rajagopal et al., 1999), and VEGF receptor-associated protein (Wu et al., 2000). The mouse TSAd gene is designated $s h 2 d 2 a$. For clarity, we designate both human and mouse gene and protein as TSAd. C57BL/6 WT mice were purchased from B\&K Scanbur.Tsad ${ }^{-1-}$ mice (Rajagopal et al., 1999 ) in the C57BL/6 background (backcrossed 10 generations) were provided by J.A. Bluestone (University of Chicago, Chicago, IL), and subsequently propagated at the local animal facility under laminar airflow conditions with a $12-\mathrm{h}$ light/dark cycle at a temperature of $22-25^{\circ} \mathrm{C}$. All animal work was approved by the Uppsala University board of animal experimentation. Analyses were performed on mice of $\sim 6$ mo of age.

Peptide spot array analysis. Peptide arrays were synthesized on nitrocellulose membranes using a MultiPep automated peptide synthesizer (INTAVIS Bioanalytical Instruments) as previously described (Kramer et al., 1999; Frank, 2002). Peptide array membranes were probed with GST-tagged SH2 domains $(2-40 \mu \mathrm{g} / \mathrm{ml})$ and blotted with mouse anti-GST antibody (Santa Cruz Biotechnology, Inc.) and anti-mouse HRP secondary antibody followed by chemiluminescent detection.

NanoPro Technology. HDMECs treated with VEGF for $7 \mathrm{~min}$ at $37^{\circ} \mathrm{C}$ were lysed in RIPA buffer containing phosphatase and protease inhibitors (ProteinSimple). The cell lysates were clarified by centrifugation, and protein concentration was determined using the BCA Protein Assay kit (Thermo Fischer Scientific). Samples were run in triplicate. Lysates were mixed with ampholyte premix ( $\mathrm{pH}$ 5-8) and fluorescent $\mathrm{pI}$ standards ( $\mathrm{pI}$ Standard Ladder 3) before being loaded into the NanoPro1000 system (ProteinSimple) for analysis. Isoelectric focusing was performed in capillaries filled with a mixture of cell lysate $(0.05-0.1 \mathrm{mg} / \mathrm{ml}$ protein), fluorescently labeled $\mathrm{pI}$ standards, and ampholytes. The separated proteins were cross-linked to the capillary wall using UV light followed by immunoprobing with anti-Src pY418 (Invitrogen), anti-Src pY527 (Cell Signaling Technology), and anti-Src (Abcam) antibodies. HSP-70 antibodies were run in parallel for normalization. HRPconjugated secondary antibodies (anti-rabbit HRP and anti-mouse HRP; ProteinSimple) were used to detect the signal. The signal was visualized by ECL and was captured by a charge-couple device camera. The digital image was analyzed and peak area quantified with Compass software (ProteinSimple). Some samples were enzymatically dephosphorylated by incubating $8 \mu \mathrm{g}$ cell lysate with 125 units lambda phosphatase (14-405; Millipore), for $1 \mathrm{~h}$ at $37^{\circ} \mathrm{C}$

Western blotting. Cells were lysed either in NP-40 buffer (HDMECs and human umbilical vein endothelial cells; $20 \mathrm{mM}$ Tris $\mathrm{HCl}, \mathrm{pH}$ 7.5, $150 \mathrm{mM}$ $\mathrm{NaCl}, 10 \%$ glycerol, 1\% NP-40, 2 mM EDTA, $500 \mu \mathrm{M} \mathrm{Na}_{3} \mathrm{VO}_{4}, 1 \%$ aprotinin, 
$10 \mu \mathrm{g} / \mathrm{ml}$ leupeptin, and $1 \mathrm{mM}$ phenylmethyl sulfonylfluoride) or in RIPA buffer (lung tissue; commercial RIPA buffer from ProteinSimple). The protein concentration was measured using the BCA protein detection kit (Thermo Fisher Scientific) and adjusted for equal loading. Lysates were heated to $95^{\circ} \mathrm{C}$ in sample buffer $(59 \mathrm{mM}$ Tris- $\mathrm{HCl}, \mathrm{pH} 6.8,1.5 \% \mathrm{SDS}, 4.35 \%$ glycerol, $4 \% \beta$-mercaptoethanol, $0.0025 \%$ bromophenol blue). Proteins separated by NuPage Novex $4-12 \%$ Bis-Tris Gel (Invitrogen) were transferred to nitrocellulose (Hybond-C Extra; GE Healthcare), blocked in 5\% BSA/PBS, $0.2 \%$ Tween 20 , followed by incubation with primary and HRP-conjugated secondary antibodies in $1 \% \mathrm{BSA} / \mathrm{PBS}, 0.2 \%$ Tween 20 . Information on the primary antibodies is given above. Blots were developed using ECL (GE Healthcare) and exposure to Hyperfilm ECL (GE Healthcare).

For the lung lysate analyses, WT and $t s a d^{-/-}$mice were sacrificed 1 or 20 min after mice received tail-vein injection of $5 \mu \mathrm{g}$ VEGF, followed by quick removal of lungs, which were snap-frozen before lysis.

When indicated, cells were transfected with siRNA before immunoblotting. Cells were then seeded in gelatin-coated 6 -wells $\left(10^{5}\right.$ cells/well $)$ and transfected with 60 pmol siRNA targeting $t s a d$ or stealth RNAi-negative ctr (Invitrogen) using the Lipofectamine RNAiMAX transfection reagent (Invitrogen). Experiments were done $48 \mathrm{~h}$ after siRNA transfection. The following tsad siRNA were used: sitsad1 5'-GAGGACCGAAGAAUCAAACUUUGGA-3' and sitsad 3 5'-CCAGTACAGCCCAATCATCAA-3'.

Immunostaining. Primary ECs (HDMECs) or ECs or isolated lung or liver endothelial cells) were cultured on slides precoated with $1 \mathrm{mg} / \mathrm{ml} \mathrm{col}-$ lagen. The cells were treated with or without 50 or $100 \mathrm{ng} / \mathrm{ml} \mathrm{VEGF-A165}$ for $10 \mathrm{~min}$ before fixation. The endothelial cells were fixed in $4 \%$ paraformaldehyde in PBS for 20 min, and permeabilized with $0.1 \%$ Triton X-100 in PBS for $30 \mathrm{~min}$, followed by immunofluorescence staining.

For immunostaining of the cremaster muscle, tissues were retrieved after perfusion via aorta with prewarmed sterile saline solution $\left(37^{\circ} \mathrm{C}\right)$, and then with 1\% PFA. The muscle tissue was dissected and fixed in $4 \%$ PFA in PBS for 20 min, washed six times with PBS, and permeabilized with $0.1 \%$ Triton $\mathrm{X}-100$ in PBS for $30 \mathrm{~min}$. The tissues were immunostained with goat anti-mouse VE-cadherin antibody (R\&D Systems), followed by staining with Alexa Fluor 488 donkey anti-goat antibody to visualize VE-cadherin on venules.

Miles assay. $30 \mathrm{~min}$ before Evans blue injection, mice were subjected to i.p. injection with pyrilamine maleate salt $(4 \mathrm{mg} / \mathrm{kg}$ body weight in $0.9 \%$ saline; Sigma-Aldrich) to inhibit histamine release. Mice were injected in the lateral tail vein with $100 \mu \mathrm{l}$ Evans blue $(0.5 \%$ Evans blue in sterile saline; Sigma-Aldrich), which was allowed to circulate for a total of $2 \mathrm{~h}$. VEGFA165 (100 ng in $50 \mu \mathrm{l} / \mathrm{site})$ or sterile saline were injected intradermally. 30 min after VEGF injection, the dorsal skin was excised and Evans blue was extracted by immersion in formamide buffer. To determine basal extravasation, kidney, lung, and skin were excised. The amount of Evans blue in each tissue sample was quantified by spectrometry at $620 \mathrm{~nm}$ (EMax microplate reader; Molecular Devices).

FITC-dextran perfusion assay. To analyzeVEGF-induced acute permeability responses, a $50 \mu$ l solution of VEGF-A165 (100 ng, diluted in sterile saline) or saline alone was injected i.d. in the ear, followed by injection of FITCdextran. $50 \mu \mathrm{l}$ 70-kD FITC-dextran $(50 \mathrm{mg} / \mathrm{ml}$ in PBS; Sigma-Aldrich) was administered systemically via tail vein injection. 30 min later, specimens were harvested and fixed in 4\% paraformaldehyde, followed by confocal microscopy To determine basal permeability of microvessels, specimens were harvested and analyzed $2 \mathrm{~h}$ after injection of FITC-dextran.

Microsphere extravasation assay in mouse trachea. $20 \mu \mathrm{l}$ of $30 \mathrm{~nm}$ Fluoro-Max Green Aqueous Fluorescent microspheres (Thermo Fisher Scientific) together with $80 \mu \mathrm{l}$ solution of VEGF-A165 ( $3 \mu \mathrm{g} /$ mouse) or saline were administered by tail vein injection. 30 min later, intravascular microspheres were perfused by $1 \%$ PFA in PBS via the left ventricle. For the histamine extravasation analysis, which was performed according to protocol (www.freidok.uni.freiburg.de/volltexte/6433), $100 \mathrm{~nm}$ fluorescent microspheres were injected together with histamine $(125 \mu \mathrm{g} / \mathrm{mouse})$ in a volume of $100 \mu \mathrm{l}$; perfusion was performed after 2 -min circulation. Tracheas were dissected and fixed in 4\% PFA in PBS for $2 \mathrm{~h}$, and then permeabilized with $0.3 \%$ Triton X-100 in PBS for $30 \mathrm{~min}$. They were incubated overnight at $4^{\circ} \mathrm{C}$ with rat anti-mouse CD31, followed by staining with Alexa Fluor 555 goat anti-rat antibody to visualize the vasculature. Extravasated microspheres in the region of postcapillary venules between cartilage rings were analyzed with confocal microscopy.

Isolation of lung endothelial cells. To isolate murine endothelial cells, the lung of three 3-4-wk-old mice were removed, finely minced, and digested with $1 \%$ Worthington type 1 collagenase in Dulbecco's PBS with calcium/ magnesium for $60 \mathrm{~min}$ at $37^{\circ} \mathrm{C}$. Digested tissues were further broken apart by being passed through a 14-gauge needle 4-5 times and then filtration through a $70-\mu \mathrm{m}$ cell strainer. The filtrate was incubated for $40 \mathrm{~min}$ at $4^{\circ} \mathrm{C}$ with $50 \mu \mathrm{l}$ of magnetic beads (Invitrogen) that had been conjugated with anti-mouse CD31 antibody. Cells with beads attached were collected using an MPC magnet (Invitrogen) and washed 6 to 8 times with PBS/BSA.The cells were grown in DME basal medium with $4.5 \mathrm{~g} / 1$ glucose, $1 \mathrm{mM}$ sodium pyruvate, $2 \mathrm{mM}$ glutamine, $1 \mathrm{mM}$ nonessential amino acids, 20\% FBS, $50 \mathrm{mg} / 500 \mathrm{ml}$ ECGS (Biomedical Technologies, Inc.), $0.1 \mathrm{mg} / \mathrm{ml}$ heparin, and antibiotic. The purity was $>95 \%$, as determined by counting ofVE-cadherin-positive cells.

eNOS activity assay. eNOS activity was determined using a Nitric Oxide Synthase (NOS) Assay kit (EMD) that measures conversion of radioactive $\left[{ }^{3} \mathrm{H}\right]$-L-arginine to $\left[{ }^{3} \mathrm{H}\right]$-L-citrulline. This reaction involves a five-electron oxidation of a guanidinonitrogen of L-arginine to nitric oxide (NO), together with the stoichiometric production of L-citrulline. Mouse lung tissues were harvested en bloc and homogenized in $20 \mathrm{ml}$ ice-cold $1 \mathrm{X}$ homogenization buffer containing $25 \mathrm{mM}$ Tris- $\mathrm{HCl}, 1 \mathrm{mM}$ EDTA, and $1 \mathrm{mM}$ EGTA, pH 7.4, per gram of tissue. After centrifuge for 5 in at $4^{\circ} \mathrm{C}$, the freshly prepared supernatants were used for the assay as described in the manufacturer's protocol. A small aliquot from each sample was used to determine protein concentration, and $10 \mu \mathrm{g}$ of protein lysates were used per reaction. Lung tissues from three WT and $t s a d^{-1-}$ mice were used for each time point $(1,10$, and $20 \mathrm{~min})$. Experiments were performed in triplicate. All values are presented as mean \pm SEM. A value of $\mathrm{P}<0.05$ between experimental groups was considered to represent a significant difference $(*)$.

Blood parameter measurements. The blood flow measurements were performed with a microsphere technique, as previously described and evaluated (Carlsson et al., 1996). WT and $t s a d^{-{ }^{-1}}$ mice aged 3-6 mo were anesthetized with Isoflurane and placed on an operating table heated to body temperature $\left(38^{\circ} \mathrm{C}\right)$. Polyethylene catheters were inserted into the ascending aorta, via the right carotid artery, and into the right femoral artery. The former catheter was connected to a pressure transducer (PDCR 75; Druck) to allow continuous monitoring of the mean arterial blood pressure, which was allowed to stabilize for 20-25 min. Approximately $10^{5}$ nonradioactive microspheres (EZ-Trac; Triton) with a diameter of $10 \mu \mathrm{m}$ were injected for $10 \mathrm{~s}$ via the catheter with its tip in the ascending aorta. Starting $5 \mathrm{~s}$ before the microsphere injection, and continuing for a total of $60 \mathrm{~s}$, an arterial blood reference sample was collected by free flow from the catheter in the femoral artery at a rate of $0.10 \mathrm{ml} / \mathrm{min}$. The exact withdrawal rate in each experiment was confirmed by weighing the sample.

Arterial blood was then collected from the catheter in the femoral artery and analyzed for blood $\mathrm{pH}, \mathrm{pCO}_{2}, \mathrm{pO}_{2}$, oxygen saturation, $\mathrm{S}-\mathrm{HCO}_{3}{ }^{-}$, base excess, $\mathrm{S}-\mathrm{Na}^{+}, \mathrm{S}-\mathrm{K}^{+}$, hematocrit, and hemoglobin concentration with an iStat (Abbott Scandinavia). The cassette used for this analysis requires $90 \mu \mathrm{l}$ of whole blood. Arterial blood was also used for determination of blood glucose concentrations (Medisense Test Reagent Strips; MediSense) and for serum insulin determinations with ELISA (Rat Insulin ELISA; Mercoedia AB).

The animals were euthanized, and the organs referred to in Table 1 were carefully dissected free from fat, blotted, and weighed. The microspheres in the organs and the arterial blood reference sample were visualized 
by a freeze-thawing technique and counted by an observer unaware of the origin of the samples (Jansson and Hellerström, 1981).

The blood flow values were calculated according to the formula $\mathrm{Q}_{\text {org }}=\mathrm{Q}_{\mathrm{ref}} \times N_{\text {org }} / N_{\text {ref }}$, where $\mathrm{Q}_{\text {org }}$ is organ blood flow $(\mathrm{ml} / \mathrm{min}), \mathrm{Q}_{\text {ref }}$ is withdrawal rate of the reference sample $(\mathrm{ml} / \mathrm{min}), N_{\text {org }}$ is the number of microspheres present in the organ, and $N_{\text {ref }}$ is the number of microspheres present in the reference sample (Carlsson et al., 1996).

Image analysis of VE-cadherin immunostaining of cremaster muscle vessels. Cremaster muscle tissue was harvested after vehicle or VEGFsuperfusion for $30 \mathrm{~min}$, fixed, and immunostained with antibodies against VE-cadherin. Images were acquired using a Zeiss LSM700 confocal microscope (63× NA 1.4 objective). From a Z series of confocal images of VEcadherin through a vessel, areas showing the junctions between endothelial cells that were aligned with the imaging plane were extracted and a maximum projection made in the $\mathrm{Z}$ axis, on a single side of the vessel and excluding the edges of the vessel. A binary image showing the junction was then generated by intensity thresholding. Breaks in the junction were joined semiautomatically. The midline along the junction was generated by eroding the binary image to a line (skeletonization) and spurs were removed by erosion, producing a continuous midline around each cell. In addition the outline of the binary image was generated. Images showing distances from the midline were generated using a Euclidean distance transform and a population of widths, taken as the shortest distance of each pixel on the outline to the midline, was then obtained from the distance transform. Where disconnected parts of the junction had been joined, the width was recorded as zero. The widths from individual pixels from different vessels were combined and displayed in a histogram. To eliminate any differences in the length of the outlines the distribution of widths was normalized. The histogram shows the frequency of different widths in microns as percentage of the whole population for each experimental group. Software was based on a Semper6p kernel (Synoptics).

Statistical analysis. Statistical significance between the groups was calculated using Student's two-tailed $t$ test or Mann Whitney test. A p-value $<0.05$ was considered significant. *, $\mathrm{P}<0.05 ; * *, \mathrm{P}<0.01, * * *, \mathrm{P}<0.001$.

We thank Kristin Johnson, Vascular Biology Program, Children's Hospital Boston for her professional support with the art work.

This study was supported by the Association for International Cancer Research (AICR grant no. 09-0034) and the Swedish Heart and Lung foundation to L. Claesson-Welsh, and by grants from the Knut and Alice Wallenberg foundation (Wallenberg Scholar Award to L. Claesson-Welsh), the Swedish Cancer Society (L. Claesson-Welsh), the Swedish Science Council (L. Claesson-Welsh, L. Jansson, and M. Phillipson), from the Swedish Diabetes Association (M. Phillipson and L. Jansson). MRA was supported by the American Heart Association Grant-in-Aid 10GRNT3640011. K. Gustafsson and G. Zang were supported by a grant from the Swedish Cancer foundation to Michael Welsh, Uppsala University. Funding or donation of reagents for this study was done without involvement in the design or conduct of this study in any way (collection, analysis, and interpretation of the data, or in preparation, review, or approval of the manuscript).

The authors declare no conflict of interest.

Submitted: 30 June 2011

Accepted: 15 May 2012

\section{REFERENCES}

Adam, A.P., A.L. Sharenko, K. Pumiglia, and P.A.Vincent. 2010. Src-induced tyrosine phosphorylation of VE-cadherin is not sufficient to decrease barrier function of endothelial monolayers. J. Biol. Chem. 285:70457055. http://dx.doi.org/10.1074/jbc.M109.079277

Baluk, P., A. Hirata, G. Thurston, T. Fujiwara, C.R. Neal, C.C. Michel, and D.M. McDonald. 1997. Endothelial gaps: time course of formation and closure in inflamed venules of rats. Am. J. Physiol. 272:L155-L170.

Carlsson, P.O., A. Andersson, and L. Jansson. 1996. Pancreatic islet blood flow in normal and obese-hyperglycemic (ob/ob) mice. Am. J. Physiol. 271:E990-E995.
Chen, X.L., J.O. Nam, C. Jean, C. Lawson, C.T. Walsh, E. Goka, S.T. Lim, A. Tomar, I. Tancioni, S. Uryu, et al. 2012. VEGF-induced vascular permeability is mediated by FAK. Dev. Cell. 22:146-157. http:// dx.doi.org/10.1016/j.devcel.2011.11.002

Choi, Y.B., C.K. Kim, and Y. Yun. 1999. Lad, an adapter protein interacting with the $\mathrm{SH} 2$ domain of p56lck, is required for T cell activation. J. Immunol. 163:5242-5249.

Di Lorenzo, A., C. Fernández-Hernando, G. Cirino, and W.C. Sessa. 2009. Akt1 is critical for acute inflammation and histamine-mediated vascular leakage. Proc. Natl. Acad. Sci. USA.106:14552-14557. http://dx.doi.org/ 10.1073/pnas.0904073106

Dougher-Vermazen, M., J.D. Hulmes, P. Böhlen, and B.I. Terman. 1994. Biological activity and phosphorylation sites of the bacterially expressed cytosolic domain of the KDR VEGF-receptor. Biochem. Biophys. Res. Commun. 205:728-738. http://dx.doi.org/10.1006/bbrc .1994 .2726

Drappa, J., L.A. Kamen, E. Chan, M. Georgiev, D. Ashany, F. Marti, and P.D. King. 2003. Impaired T cell death and lupus-like autoimmunity in T cell-specific adapter protein-deficient mice. J. Exp. Med. 198:809821. http://dx.doi.org/10.1084/jem.20021358

Durán, W.N., J.W. Breslin, and F.A. Sánchez. 2010. The NO cascade, eNOS location, and microvascular permeability. Cardiovasc. Res. 87:254-261. http://dx.doi.org/10.1093/cvr/cvq139

Dvorak, A.M., and D. Feng. 2001. The vesiculo-vacuolar organelle (VVO). A new endothelial cell permeability organelle. J. Histochem. Cytochem. 49:419-432. http://dx.doi.org/10.1177/002215540104900401

Dvorak, H.F., J.A. Nagy, D. Feng, L.F. Brown, and A.M. Dvorak. 1999. Vascular permeability factor/vascular endothelial growth factor and the significance of microvascular hyperpermeability in angiogenesis. Curr. Top. Microbiol. Immunol. 237:97-132. http://dx.doi.org/10.1007/ 978-3-642-59953-8_6

Eliceiri, B.P., R. Paul, P.L. Schwartzberg, J.D. Hood, J. Leng, and D.A. Cheresh. 1999. Selective requirement for Src kinases during VEGFinduced angiogenesis and vascular permeability. Mol. Cell. 4:915-924. http://dx.doi.org/10.1016/S1097-2765(00)80221-X

Esser, S., M.G. Lampugnani, M. Corada, E. Dejana, and W. Risau. 1998. Vascular endothelial growth factor induces VE-cadherin tyrosine phosphorylation in endothelial cells. J. Cell Sci. 111:1853-1865.

Feng, D., J.A. Nagy, H.F. Dvorak, and A.M. Dvorak. 2002. Ultrastructural studies define soluble macromolecular, particulate, and cellular transendothelial cell pathways in venules, lymphatic vessels, and tumor-associated microvessels in man and animals. Microsc. Res. Tech. 57:289-326. http:// dx.doi.org/10.1002/jemt.10087

Feng, J., S.M. Damrauer, M. Lee, F.W. Sellke, C. Ferran, and M.R. Abid. 2010. Endothelium-dependent coronary vasodilatation requires NADPH oxidase-derived reactive oxygen species. Arterioscler. Thromb. Vasc. Biol. 30:1703-1710. http://dx.doi.org/10.1161/ATVBAHA.110 .209726

Flynn D.C., T.H. Leu, A.B. Reynolds, and J.T. Parsons. 1993. Identification and sequence analysis of cDNAs encoding a 110-kilodalton actin filament-associated pp60src substrate. Mol. Cell. Biol.. 13:7892-7900.

Frank, R. 2002. High-density synthetic peptide microarrays: emerging tools for functional genomics and proteomics. Comb. Chem. High Throughput Screen. 5:429-440.

Fukumura, D., T. Gohongi, A. Kadambi,Y. Izumi,J.Ang, C.O.Yun, D.G. Buerk, P.L. Huang, and R.K. Jain. 2001. Predominant role of endothelial nitric oxide synthase in vascular endothelial growth factor-induced angiogenesis and vascular permeability. Proc. Natl. Acad. Sci. USA. 98:2604-2609. http://dx.doi.org/10.1073/pnas.041359198

Fulton, D., J.P. Gratton, T.J. McCabe, J. Fontana, Y. Fujio, K. Walsh, T.F. Franke, A. Papapetropoulos, and W.C. Sessa. 1999. Regulation of endothelium-derived nitric oxide production by the protein kinase Akt. Nature. 399:597-601. http://dx.doi.org/10.1038/21218

Gavard,J., and J.S. Gutkind.2006.VEGF controls endothelial-cell permeability by promoting the beta-arrestin-dependent endocytosis of VE-cadherin. Nat. Cell Biol. 8:1223-1234. http://dx.doi.org/10.1038/ncb1486

Granum, S., V. Sundvold-Gjerstad, K.Z. Dai, K.M. Kolltveit, K. Hildebrand, H.S. Huitfeldt, T. Lea, and A. Spurkland. 2006. Structure function analysis of SH2D2A isoforms expressed in T cells reveals a crucial role for 
the proline rich region encoded by SH2D2A exon 7. BMC Immunol. 7:15. http://dx.doi.org/10.1186/1471-2172-7-15

Granum, S., T.C. Andersen, M. Sørlie, M. Jørgensen, L. Koll, T. Berge, T. Lea, B. Fleckenstein, A. Spurkland, and V. Sundvold-Gjerstad. 2008. Modulation of Lck function through multisite docking to $\mathrm{T}$ cellspecific adapter protein. J. Biol. Chem. 283:21909-21919. http://dx.doi .org/10.1074/jbc.M800871200

Holmqvist, K., M.J. Cross, C. Rolny, R. Hägerkvist, N. Rahimi, T. Matsumoto, L. Claesson-Welsh, and M. Welsh. 2004. The adaptor protein shb binds to tyrosine 1175 in vascular endothelial growth factor (VEGF) receptor-2 and regulates VEGF-dependent cellular migration. J. Biol. Chem. 279:22267-22275. http://dx.doi.org/10.1074/jbc M312729200

Jansson, L., and C. Hellerström. 1981. A rapid method of visualizing the pancreatic islets for studies of islet capillary blood flow using nonradioactive microspheres. Acta Physiol. Scand. 113:371-374. http://dx.doi .org/10.1111/j.1748-1716.1981.tb06909.x

Koch, S., S. Tugues, X. Li, L. Gualandi, and L. Claesson-Welsh. 2011. Signal transduction by vascular endothelial growth factor receptors. Biochem. J. 437:169-183. http://dx.doi.org/10.1042/BJ20110301

Kramer A., U. Reineke, L. Dong, B. Hoffmann, U. Hoffmüller, D. Winkler, R. Volkmer-Engert, and J. Schneider-Mergener. 1999. Spot synthesis: observations and optimization. J. Pept. Res. 54:319-327.

Lambeng, N.,Y. Wallez, C. Rampon, F. Cand, G. Christé, D. Gulino-Debrac, I. Vilgrain, and P. Huber. 2005. Vascular endothelial-cadherin tyrosine phosphorylation in angiogenic and quiescent adult tissues. Circ. Res. 96:384-391. http://dx.doi.org/10.1161/01.RES.0000156652.99586.9f

Laramée, M., C. Chabot, M. Cloutier, R. Stenne, M. Holgado-Madruga, A.J. Wong, and I. Royal. 2007. The scaffolding adapter Gab1 mediates vascular endothelial growth factor signaling and is required for endothelial cell migration and capillary formation. J. Biol. Chem. 282:77587769. http://dx.doi.org/10.1074/jbc.M611327200

Lin, M.I., J. Yu, T. Murata, and W.C. Sessa. 2007. Caveolin-1-deficient mice have increased tumor microvascular permeability, angiogenesis, and growth. Cancer Res. 67:2849-2856. http://dx.doi.org/10.1158/00085472.CAN-06-4082

Lu,Y.,Y. Xiong,Y. Huo, J. Han, X.Yang, R. Zhang, D.S. Zhu, S. Klein-Hessling, J. Li, X. Zhang, et al. 2011. Grb-2-associated binder 1 (Gab1) regulates postnatal ischemic andVEGF-induced angiogenesis through the protein kinase A-endothelial NOS pathway. Proc. Natl.Acad. Sci. USA. 108:29572962. http://dx.doi.org/10.1073/pnas.1009395108

Matsumoto, T., S. Bohman, J. Dixelius, T. Berge, A. Dimberg, P. Magnusson, L. Wang, C. Wikner, J.H. Qi, C. Wernstedt, et al. 2005.VEGF receptor-2 Y951 signaling and a role for the adapter molecule TSAd in tumor angiogenesis. EMBO J. 24:2342-2353. http://dx.doi.org/10.1038/sj.emboj.7600709

Mehta, D., and A.B. Malik. 2006. Signaling mechanisms regulating endothelial permeability. Physiol. Rev. 86:279-367. http://dx.doi.org/10.1152/ physrev.00012.2005

Meyer, R.D., C. Latz, and N. Rahimi. 2003. Recruitment and activation of phospholipase Cgamma1 by vascular endothelial growth factor receptor-2 are required for tubulogenesis and differentiation of endothelial cells. J. Biol. Chem. 278:16347-16355. http://dx.doi.org/10.1074/jbc. M300259200

Meyer, R.D., D.B. Sacks, and N. Rahimi. 2008. IQGAP1-dependent signaling pathway regulates endothelial cell proliferation and angiogenesis. PLoS ONE. 3:e3848. http://dx.doi.org/10.1371/journal.pone.0003848

Nagy, J.A., L. Benjamin, H. Zeng, A.M. Dvorak, and H.F. Dvorak. 2008. Vascular permeability, vascular hyperpermeability and angiogenesis. Angiogenesis. 11:109-119. http://dx.doi.org/10.1007/s10456-0089099-z

Rajagopal, K., C.L. Sommers, D.C. Decker, E.O. Mitchell, U. Korthauer, A.I. Sperling, C.A. Kozak, P.E. Love, and J.A. Bluestone. 1999. RIBP, a novel Rlk/Txk- and itk-binding adaptor protein that regulates T cell activation. J. Exp. Med. 190:1657-1668. http://dx.doi .org/10.1084/jem.190.11.1657

Roskoski, R.Jr.2005. Src kinase regulation by phosphorylation and dephosphorylation. Biochem. Biophys. Res. Commun. 331:1-14. http://dx.doi .org/10.1016/j.bbrc.2005.03.012
Ruan, G.X., and A. Kazlauskas. 2012. Axl is essential for VEGF-A-dependent activation of PI3K/Akt. EMBO J. 31:1692-1703. http://dx.doi .org/10.1038/emboj.2012.21

Sakurai, Y., K. Ohgimoto, Y. Kataoka, N. Yoshida, and M. Shibuya. 2005. Essential role of Flk-1 (VEGF receptor 2) tyrosine residue 1173 in vasculogenesis in mice. Proc. Natl. Acad. Sci. USA. 102:1076-1081. http:// dx.doi.org/10.1073/pnas.0404984102

Scheppke, L., E. Aguilar, R.F. Gariano, R. Jacobson, J. Hood, J. Doukas, J. Cao, G. Noronha, S.Yee, S. Weis, et al. 2008. Retinal vascular permeability suppression by topical application of a novel VEGFR2/Src kinase inhibitor in mice and rabbits. J. Clin. Invest. 118:2337-2346.

Senger, D.R., S.J. Galli, A.M. Dvorak, C.A. Perruzzi, V.S. Harvey, and H.F. Dvorak. 1983. Tumor cells secrete a vascular permeability factor that promotes accumulation of ascites fluid. Science. 219:983-985. http:// dx.doi.org/10.1126/science. 6823562

Sessa, W.C. 2009. Molecular control of blood flow and angiogenesis: role of nitric oxide. J. Thromb. Haemost. 7(Suppl 1):35-37. http://dx.doi.org/ 10.1111/j.1538-7836.2009.03424.x

Solowiej, J., S. Bergqvist, M.A. McTigue, T. Marrone, T. Quenzer, M. Cobbs, K. Ryan, R.S. Kania, W. Diehl, and B.W. Murray. 2009. Characterizing the effects of the juxtamembrane domain on vascular endothelial growth factor receptor-2 enzymatic activity, autophosphorylation, and inhibition by axitinib. Biochemistry. 48:7019-7031. http://dx.doi.org/ 10.1021/bi900522y

Spurkland, A., J.E. Brinchmann, G. Markussen, F. Pedeutour, E. Munthe, T. Lea, F. Vartdal, and H.C. Aasheim. 1998. Molecular cloning of a T cell-specific adapter protein (TSAd) containing an Src homology (SH) 2 domain and putative SH3 and phosphotyrosine binding sites. J. Biol. Chem. 273:4539-4546. http://dx.doi.org/10.1074/jbc.273.8.4539

Stohrer, M., Y. Boucher, M. Stangassinger, and R.K. Jain. 2000. Oncotic pressure in solid tumors is elevated. Cancer Res. 60:4251-4255.

Sundvold-Gjerstad, V., S. Granum, T. Mustelin, T.C. Andersen, T. Berge, M.J. Shapiro, V.S. Shapiro, A. Spurkland, and T. Lea. 2005. The C terminus of $\mathrm{T}$ cell-specific adapter protein (TSAd) is necessary for TSAd-mediated inhibition of Lck activity. Eur. J. Immunol. 35:1612-1620. http://dx.doi .org/10.1002/eji.200425638

Sundvold-Gjerstad, V., S. Granum, T. Berge, T.B.C. Andersen, K.M. Kolltveit, and A. Spurkland. 2007. T cell specific adapter protein in cell signalling and autoimmunity. In Lymphocyte Activation and Signal Transduction. Noah Isakov, ed. Transworld Research Network. Pages 211-220.

Takahashi, T., S. Yamaguchi, K. Chida, and M. Shibuya. 2001. A single autophosphorylation site on KDR/Flk-1 is essential for VEGF-Adependent activation of PLC-gamma and DNA synthesis in vascular endothelial cells. EMBO J. 20:2768-2778. http://dx.doi.org/10 $.1093 / \mathrm{emboj} / 20.11 .2768$

Tzima, E., M. Irani-Tehrani, W.B. Kiosses, E. Dejana, D.A. Schultz, B. Engelhardt, G. Cao, H. DeLisser, and M.A. Schwartz. 2005. A mechanosensory complex that mediates the endothelial cell response to fluid shear stress. Nature. 437:426-431. http://dx.doi.org/10.1038/ nature 03952

Vandenbroucke, E., D. Mehta, R. Minshall, and A.B. Malik. 2008. Regulation of endothelial junctional permeability. Ann. N. Y. Acad. Sci. 1123:134-145. http://dx.doi.org/10.1196/annals.1420.016

Vestweber, D. 2012. Novel insights into leukocyte extravasation. Curr. Opin. Hematol. 19:212-217. http://dx.doi.org/10.1097/MOH $.0 \mathrm{~b} 013 \mathrm{e} 3283523 \mathrm{e} 78$

Wallez, Y., F. Cand, F. Cruzalegui, C. Wernstedt, S. Souchelnytskyi, I. Vilgrain, and P. Huber. 2007. Src kinase phosphorylates vascular endothelialcadherin in response to vascular endothelial growth factor: identification of tyrosine 685 as the unique target site. Oncogene. 26:1067-1077. http://dx.doi.org/10.1038/sj.onc.1209855

Warner, A.J., J. Lopez-Dee, E.L. Knight, J.R. Feramisco, and S.A. Prigent. 2000. The Shc-related adaptor protein, Sck, forms a complex with the vascularendothelial-growth-factor receptor KDR in transfected cells. Biochem. J. 347:501-509. http://dx.doi.org/10.1042/0264-6021:3470501

Weis, S.M., and D.A. Cheresh. 2005. Pathophysiological consequences of VEGF-induced vascular permeability. Nature. 437:497-504. http:// dx.doi.org/10.1038/nature03987 
Weis, S., J. Cui, L. Barnes, and D. Cheresh. 2004a. Endothelial barrier disruption by VEGF-mediated Src activity potentiates tumor cell extravasation and metastasis. J. Cell Biol. 167:223-229. http://dx.doi.org/ $10.1083 /$ jcb. 200408130

Weis, S., S. Shintani, A. Weber, R. Kirchmair, M. Wood, A. Cravens, H. McSharry, A. Iwakura, Y.S. Yoon, N. Himes, et al. 2004b. Src blockade stabilizes a Flk/cadherin complex, reducing edema and tissue injury following myocardial infarction. J. Clin. Invest. 113:885-894.

Wu, L.W., L.D. Mayo, J.D. Dunbar, K.M. Kessler, O.N. Ozes, R.S. Warren, and D.B. Donner. 2000.VRAP is an adaptor protein that binds KDR, a receptor for vascular endothelial cell growth factor. J. Biol. Chem 275:6059-6062. http://dx.doi.org/10.1074/jbc.275.9.6059

Xiao, K., J. Garner, K.M. Buckley, P.A.Vincent, C.M. Chiasson, E. Dejana, V. Faundez, and A.P. Kowalczyk. 2005. p120-Catenin regulates clathrindependent endocytosis of VE-cadherin. Mol. Biol. Cell. 16:5141-5151. http://dx.doi.org/10.1091/mbc.E05-05-0440

Zhao, J., W. Wang, C.H. Ha, J.Y. Kim, C. Wong, E.M. Redmond, A. Hamik, M.K. Jain, G.S. Feng, and Z.G. Jin. 2011. Endothelial Grb2-associated binder 1 is crucial for postnatal angiogenesis. Arterioscler. Thromb. Vasc. Biol. 31:1016-1023. http://dx.doi.org/10.1161/ATVBAHA.111.224493 